\title{
Water demands for electricity generation in the U.S.: modeling different scenarios for the water-energy nexus
}

\author{
Lu Liu ${ }^{1}$, Mohamad Hejazi ${ }^{1}$, Pralit Patel ${ }^{1}$, Page Kyle ${ }^{1}$, Evan Davies ${ }^{2}$, Yuyu Zhou ${ }^{1}$, Leon Clarke ${ }^{1}$, \\ James Edmonds ${ }^{1}$ \\ ${ }^{1}$ Joint Global Change Research Institute, Pacific Northwest National Laboratory, 5825 \\ University Research Court, Suite 3500, College Park, MD 20740, USA \\ ${ }^{2}$ Department of Civil and Environmental Engineering, University of Alberta, 3-133 \\ Markin/CNRL Natural Resources Engineering Facility, Edmonton, Alberta T6G 2W2, Canada
}

\begin{abstract}
Water withdrawal for electricity generation in the United States accounts for approximately half the total freshwater withdrawal. With steadily growing electricity demands, a changing climate, and limited water supplies in many water-scarce states, meeting future energy and water demands poses a significant socio-economic challenge. Employing an integrated modeling approach that captures the energy-water interactions at regional and national scales can improve our understanding of the key drivers that govern those interactions and the role of national policies. In this study, the Global Change Assessment Model (GCAM), a technologically-detailed integrated model of the economy, energy, agriculture and land use, water, and climate systems, was extended to model the electricity and water systems at the state level in the U.S. (GCAM-USA). GCAM-USA was employed to estimate future state-level electricity generation and consumption, and their associated water withdrawals and consumption under a set of seven scenarios with extensive detail on the generation fuel portfolio, cooling technology mix, and their associated water use intensities. These seven scenarios were explored to investigate the implications of socioeconomic development and growing electricity demands, cooling system transitions, adoption of water saving technologies, climate mitigation policy and electricity trading options on future water demands of the U.S. electric-sector. Our findings
\end{abstract}


include: 1) decreasing water withdrawals and increasing water consumption from the conversion from open-loop to closed-loop cooling systems; 2) different energy-sector water demand behaviors with alternative pathways to the mitigation goal; 3) open trading of electricity benefiting energy-scarce yet demand-intensive states; 4) across-state homogeneity under certain driving forces (e.g., climate mitigation and water saving technologies) and mixed effects under other drivers (e.g,, electricity trade); and 5) a clear trade-off between water consumption and withdrawal for the electricity sector in the U.S. The paper discusses this withdrawal-consumption trade-off in the context of current national policies and regulations that favor decreasing withdrawals (and increasing consumptive use), and the role of water-saving technologies. The study also clearly shows that climate mitigation strategies focusing on CCS and nuclear power will have less favorable water consumption effects than strategies that support renewable energy and water saving technologies. The highly-resolved nature of this study, both geographically and technologically, provides a useful platform to address scientific and policy-relevant and emerging issues at the heart of the water-energy nexus in the U.S.

\section{Introduction}

The power generation industry in the United States is a water-intensive sector that requires large volumes of water for cooling purposes. Approximately $41 \%$ of the total freshwater withdrawal in the U.S. is attributed to the electricity sector, followed by irrigation at $37 \%$ [Kenny et al., 2009]. From 1955 to 2005, U.S. power plants' fresh water withdrawal grew from an estimated annual volume of $78 \mathrm{~km}^{3}$ [MacKichan, 1957] to $197 \mathrm{~km}^{3}$ [Kenny et al., 2009] (152\% increase). Similarly, from 1975 to 1995 , U.S. electric-sector water consumption grew by $70 \%$ [Murray and Reeves, 1977; Solley et al., 1998]. These changes are not homogeneous. Some states experienced greater rates of expansion than others; in particular arid regions, and regions 
with expanding populations, are grappling with mounting regional competition for water resources. While electricity generation itself will likely increase over the coming decades [EIA, 2013a], it is unclear how the U.S. electric-sector water demand will change in the near future both nationally and at the state level. This uncertainty highlights the importance of understanding the interactions between the electricity and water systems and the potential effects of a multitude of key factors [Byers et al., 2014; Hejazi et al., 2014], including water-saving adaptations, climate mitigation policies, capital stock turnover, and technological advances [Davies et al., 2013; Kyle et al., 2013].

Several studies have estimated present and future water demand for electricity generation in the U.S. [Davies et al., 2013; EPRI, 2000; 2010; Macknick et al., 2012a; NETL, 2009; 2011]. Most water demand at thermoelectric power plants is for cooling and re-condensing steam, but the demands also include boiler make-up water and other process uses. In this study, electricsector water demands also include evaporation from hydropower reservoirs and water used for washing solar panels. Such demand is typically defined in terms of water withdrawal and/or water consumption. Water withdrawal is the amount of water withdrawn from a surface or ground water source; after use, part of it goes back to its source as return flow. Water consumption, on the other hand, is defined as the net removal of water from the immediate environment [Vickers, 2002], and in the context of electricity generation, mostly consists of evaporation, whether on-site (from cooling towers or cooling ponds) or from the proximate body of water (from evaporation at reservoirs or from increased water temperatures).

The Electric Power Research Institute (EPRI) (2000) concluded that the relative fraction of freshwater consumption by power plants will shrink in the next half century in the U.S., compared to other water demand sectors. Their sensitivity analysis indicated that the shift from 
coal and nuclear to natural gas appeared to greatly reduce water consumption for power generation. However, their electricity demand projection was based on existing generation and transmission, and omitted construction of new generation and transmission. EPRI (2010) presented current and future water withdrawal requirements, resolved at the county-level across the U.S., and stressed the key role of water-use efficiency in reducing water stress. However, the resulting water withdrawal projections were based on an extrapolation of current trends, and did not explicitly address the role of technology in determining the water intensity of power production. The National Energy Technology Laboratory (NETL) (2009; 2011) examined present and future U.S. electric-sector withdrawals to 2030 for a set of scenarios that addressed uncertainties in future thermoelectric power generation, retirement and retrofit rates of existing power plants, and the types of cooling systems that will be installed in the future. Their analysis was conducted at the scale of North American Electric Reliability Council (NERC) regions, based on Energy Information Administration (EIA) form 767 data (http://www.eia.gov/electricity/data/eia767/) from 2000 and 2005. Macknick et al. (2012) projected water demand for electricity generation at the USGS regional scale (http://water.usgs.gov/GIS/huc.html) under carbon-constrained scenarios, with the electricity supply projected by the national electricity capacity expansion model ReEDS. Their study revealed declining water withdrawal and consumption over time, and attributed these reductions to their assumptions for the generation fuel portfolio, which heavily favored low-carbon technologies over thermoelectric generation. Davies et al. (2013) explored scenarios of U.S. and global water withdrawal and consumption for electricity generation up to 2095 using GCAM*, projected decreases in water withdrawal and increases in consumptive use over the century, and concluded that the adoption of water-saving technologies, shifts in plant cooling technologies, 
and variations in water-use intensities among generation technologies will substantially affect water demands in the future.

This study extends the work of Davies et al. (2013) by building a 50-state electricity water demand module within the GCAM-USA framework, and by establishing a more detailed disaggregation on generation type, fuel portfolio, and cooling technology mix. We employ this GCAM-USA framework to assess the roles of various factors - such as socioeconomics and growing electricity demands, the adoption of climate mitigation policies, the transition of cooling systems, electricity trading options, and the adoption of water saving technologies [Davies et al., 2013; Kyle et al., 2013] - on U.S. electric-sector water demand at the state level through a set of seven scenarios. The present study builds on existing literature by integrating the level of spatial and technological detail of EPRI (2010), NETL (2011), and Macknick et al. (2012) into the system-wide, global, and long-term consistency of Davies et al. (2013). We update the underlying cooling technology mix data to the bottom-up assessment of Averyt et al. (2011), while ensuring top-down consistency with the USGS (http://water.usgs.gov/watuse/data/) statelevel estimates. Our main additions to the existing literature are (1) the integration of a full energy-system model that also includes electricity demands and non-U.S. regions, which are less well represented in electricity capacity-expansion models, and (2) higher geographic and technological resolution, based on the UCS dataset that is designed to address many of the inconsistencies in the responses to EIA's 767 and 860 forms. The proposed framework and scenarios offer a unique platform to improve our understanding of the relative importance of driving forces that govern the U.S. electricity water demand into the future, and to investigate the regional implications of complexities in the U.S. energy-water nexus. The method is applicable 
to regions outside the U.S., but it would require high-quality datasets that permit the same level of technological disaggregation used in this study.

\section{GCAM-USA}

GCAM is a global integrated assessment model developed and maintained at the Pacific Northwest National Laboratory, designed for long-term analysis of energy supply and demand, agriculture and land use, greenhouse gas emissions, and climate. GCAM is also a community model which can be obtained at http://www.globalchange.umd.edu/models/gcam/download/.

For the purposes of the present study, only the components of the model relevant for the assessment of the electric-sector water demand are described; the full description of GCAM can be found on the GCAM Wiki (http://wiki.umd.edu/gcam/index.php/Main_Page), and in a series of publications [Brenkert et al., 2003; Clarke et al., 2007; Edmonds and Reilly, 1985; Kim et al., 2006]. GCAM-USA builds on GCAM by extending the framework to model electricity markets and their water demands at the U.S. state level instead of the original national level.

There are nine fuel types, or sources of energy, for electricity generation in GCAM-USA: coal, gas, oil, biomass, nuclear, geothermal, hydro, wind, and solar. They can be used to produce power using a wider range of production technology options that are also tracked in GCAMUSA. Future regional electricity demand is driven by growth in demand for energy services by the buildings, industrial, and transportation sectors, which in turn are driven by exogenous assumptions about population and income in each region, modified by technological aspects of energy service provision [Zhou et al., 2014]. GCAM-USA calculates the annual electricity generation by fuel type and generation technology in each of the 50 states at 5-year intervals from 2005 to 2095, and includes power plant retirements and new additions. The new power production capacity mix depends at least in part on expected production costs for each fuel- 
technology option. Capital stocks are modeled explicitly. Thus, while the generation mix of new builds in any time period depends largely on the characteristics of available technologies and on energy prices in that time period, the total generation mix also incorporates the decisions made in prior time periods.

To place our energy sector modeling in context, we compare total U.S. projections for electricity consumption to other recent projections, starting with the U.S. EIA National Energy Modeling System (NEMS) [EIA, 2013b]. Overall U.S. total electricity demand (for all states) in our reference scenario grows by $24 \%$ from 2010 to 2040 , which is very similar to the growth in the most recent NEMS scenario of $27 \%$. U.S. electricity demand projections from a number of sources are also compared in the EIA Annual Energy Outlook 2013 [EIA, 2013a]. The GCAMUSA electricity demand increase of $19 \%$ from 2010 to 2035 compares to increases of $21 \%$ (EVA), 42\% (IHSGI), 11\% (INFORUM), 29\% (ICF) and 17\% (NREL).

Power plant cooling systems are typically grouped into four categories:

1) Once-through flow: Once-through flow cooling systems run water from a source through a cooling loop, discharging it back to the source at a higher temperature. Due to the magnitude of the intake flow, this cooling system type is mostly used at power plants located on large bodies of water (e.g., lakes, large rivers, or the sea). In the U.S., this cooling technology is found in most thermoelectric power plants constructed in the Eastern half of the country prior to the 1980's, but since then has become less common due to the implementation of the Clean Water Act, which targets thermal pollution [EPRI, 2007]. While very little evaporation takes place on-site, the discharge of hot water increases evaporation from the water source; this additional evaporation is included in our estimates of water consumption. Note that this study is focused only on freshwater demands, so the use of seawater for cooling is not tracked. 
2) Recirculating: Recirculating cooling systems withdraw comparatively small volumes of water, but circulate it through the cooling loop many times and achieve heat displacement primarily through evaporation rather than increased water temperature. For this reason, the water consumption intensities of power plants with recirculating cooling tend to be several times higher than similar plants with once-through flow cooling. Recirculating cooling is becoming prominent and new power plants are typically equipped with recirculating cooling rather than once-through cooling.

3) Cooling ponds: Cooling ponds are used where sufficient land is available as an alternative to cooling towers (recirculating). Similar to cooling towers, plants reuse water after its recirculation and cooling in the pond. New water is added to the recirculating systems to replace evaporative losses. In this study, cooling pond and recirculating cooling are reported together as closed-loop systems [Kenny et al., 2009].

4) Dry cooling: Power plants equipped with dry cooling systems do not consume cooling water; instead, heat from electricity generation is dissipated to the open air. However, dry cooling is much less efficient than wet cooling towers and has higher capital costs [NETL, 2009]. This type of cooling is seen primarily in water constrained areas.

In GCAM-USA, the electric-sector water demand in each state and modeled time period is calculated by the following equation:

$$
Q_{f}=E_{f} \times \sum\left(S_{f}^{t} \times C_{f}^{t}\right)
$$

where $t$ and $f$ are indices for the type of cooling technology and fuel; $Q_{f}$ is the cooling water demand; $E_{f}$ is the electricity generation; and $S_{f}^{t}$ is the share of cooling technology $t$ for power plants that use fuel type $f . C_{f}^{t}$ denotes the cooling water withdrawal or consumption per unit of electricity generated for the power plant that uses fuel type $f$ and cooling technology $t$. $E_{f}$ varies 
by state, time and scenario. $S_{f}^{t}$ is region- and scenario-specific but fixed throughout the projection period. $C_{f}^{t}$ is an exogenous input applied across all states and is kept constant into the future except under advanced tech I and II scenarios. Water use is also tracked for nonthermoelectric plants: evaporation from hydro power plants and washing of solar panels.

Population data were obtained from United Nations, Department of Economic and Social Affairs (http://esa.un.org/unpd/wpp/unpp/panel_population.htm). GCAM-USA calculates statelevel electricity generation and consumption values by fuel and generation technology endogenously. Cooling technology mix data for existing power plants are from Averyt et al. (2011). Water-use intensities are adopted from Davies et al. (2013). More details on the data descriptions are given in the supplemental materials.

In this study, water availability is not a constraining variable and climate change impacts on water temperature and consequently power plant water demands are not modeled. Instead, our focus is on how evolving demographics and power sector technology will influence state-level water withdrawals and consumption for electricity generation in the United States. The foundation of the analysis is a set of scenarios designed to explore selected uncertainties in future technological development and attempts to mitigate climate change.

\section{Scenarios}

Of the seven scenarios assessed in this study, detailed below and shown in Table 1, three (\#2, \#3, and \#4) address uncertainties related to cooling system alternatives. Because different systems have very different water demand intensities - spanning several orders of magnitude, in fact [Macknick et al., 2012b] - and because the trade-offs between capital costs, power plant efficiencies, and water requirements of the different cooling system options cannot be appropriately modeled without explicit consideration of water prices or supply limitations, we 
use alternative scenarios to investigate the effects of different cooling system choices. These scenarios span a range of future outcomes relevant for the types and levels of water demands by individual power technologies, whether due to future technology development, laws, or actual or perceived constraints on the availability of water for producing power. Two additional scenarios (\#5 and \#6) address climate change mitigation policy, which is expected to have significant consequences for technology choice in the power sector even at low levels of mitigation, or low carbon prices [Clemmer et al., 2013; Marcucci and Turton, 2014]. Reducing power sector emissions may also have consequences for the water demands of the sector as a whole [Webster et al., 2013]. A final sensitivity analysis (\#7) addresses the importance for water demands of the model set-up. Specifically, while global integrated assessment models typically balance supplies and demands at the national or multi-national level [Brenkert et al., 2003; Easterling, 1997; Loulou and Labriet, 2008; Messner and Schrattenholzer, 2000], U.S.-focused energy and electricity models tend to use between 10 and 20 electricity grid regions [EIA, 2013b; EPA, 2006; Short et al., 2011]. This scenario reveals the value of modeling sub-national electricity markets for spatial allocations and magnitudes of future power-sector water demands.

1) Reference scenario: This scenario makes a variety of assumptions that are shared with the other six scenarios, including, for example, future state-level demographics, renewable energy resources, technology costs and availabilities, fossil resource availabilities, and elasticity of substitution between different fuels in each of dozens of sectors. Population trends are shown in Figure S8. Building-, industry-, and transportation sector electricity demands are derived from service-based representations in which electric-powered technologies may compete with refined liquid fuels or various primary energy forms. Technological efficiencies are generally modeled 
as improving in the future, but the growth in service demands generally results in steadily increasing electricity demands to 2100 (Figure S5).

In the reference scenario, the power sector remains heavily reliant on coal, gas, and nuclear energy, with about 10\% of the supply coming from wind power (Figure S5(b)). Cooling system shares from 2010 to 2095 are assumed equal to the average for new investment from 2000 to 2008 for each state in Averyt et al. (2011). This is intended to continue the current legal implementation of Clean Water Act Section 316(b).

2) Frozen scenario: Electricity demand evolves as in the reference scenario, but the future cooling technology mix remains the same here for all new investment from 2010 to 2095 as the stock averages by fuel in 2005. This scenario thus allows a relatively high share of new investment to use once-through flow cooling systems, and as such it serves as an upper bound on the future water withdrawals by the power sector. However, with technological change in the power sector (e.g., switching from pulverized coal to natural gas combined-cycle), the average water intensity of the power sector may nevertheless change from 2005 to 2095.

3) Advanced tech I: Electricity demand and generation by technology are the same as in the reference scenario. This scenario differs from the reference only in the application of watersaving technologies in the power sector. Starting in 2010, all new-built power generation uses advanced water-saving technologies as described in Feeley et al. (2008) [Feeley Iii et al., 2008].

4) Advanced tech II: Similar to advanced tech I scenario, but with increases in shares of dry cooling to $30 \%$ in Arizona, California, Texas, Utah, and Nevada, and proportional reductions in shares of closed-loop cooling. The climate in these states is typically drier than the rest of the U.S., and fresh water resources are less abundant. 
5) RCP 4.5_NucCCS: This represents effects on water demands of a climate mitigation policy scenario that stabilizes radiative forcing to $4.5 \mathrm{~W} / \mathrm{m}^{2}$ in 2100 [Thomson et al., 2011] by assuming a significant expansion of nuclear power and CCS technology in the fuel and technology mix. Electricity prices and demand levels in this scenario are different from the baseline scenario with the implementation of an economy-wide carbon price. However, as has been documented elsewhere [Paltsev et al., 2008; Ross et al., 2009], electricity demand in a carbon-constrained economy is generally similar and often slightly higher than without any climate policy, in spite of higher electricity prices, as electricity is substituted for direct combustion of hydrocarbon fuels in the buildings, industry, and transportation sectors.

6) RCP 4.5_RE: This represents effects on water demands of a climate mitigation policy scenario that stabilizes radiative forcing to $4.5 \mathrm{~W} / \mathrm{m}^{2}$ in 2100 by substituting thermal generation with renewable energies such as wind, solar PV, and CSP. New capacities will not include nuclear energy and CCS technology; instead, the deployment of renewable energies will substantially reduce carbon emissions and water use, since renewable energies are much less water-intensive than hydrocarbon fuels and nuclear energy.

7) Full trade: This scenario investigates the consequences for water demand of reconciling electricity supply and demand at the national scale, which implicitly allows the electricity demands in any state to be met by generation in any other state. Because the economic conditions facing the power sector are unique to each state - based on, for example, the installed capital stock, fuel prices and availabilities, renewable resources, and demand levels - it is possible that the levels and geographic locations of water demands will be quite different in switching from a regionally-constrained model to one with a national-scale economic resolution. 


\section{Results and analysis}

Historical estimates and comparison with USGS

Historical water withdrawals and consumption for electricity generation were computed using Equation (1) for each of the states. U.S.-level results show a water withdrawal estimate for $2005\left(204 \mathrm{~km}^{3} /\right.$ year) that is close to the USGS-reported value $\left(197 \mathrm{~km}^{3} /\right.$ year) (Figure S4(a)) [Kenny et al., 2009]. At the state level, the estimated water withdrawal also shows good agreement (a correlation coefficient equal to 0.94) with the USGS estimates (http://water.usgs.gov/watuse/data/) for the base year of 2005 (Figure S4(b)). Consumption values are also compared against USGS estimates to 1995, the last period with published USGS estimates of consumptive water use. Our consumptive use estimates prior to 2000 demonstrate acceptable agreement with the USGS estimation (Figures S4(c) and S4(d)).

\section{Future Projections}

U.S. electricity generation was projected under each of the seven scenarios; recall that the frozen and advanced tech I and II scenarios share the reference scenario's fuel mix. Electricity generation increased in all projections, with RCP 4.5_NucCCS having the greatest increase by the end of the century (82\% from 2005) (Figure S5(a)). The intensifying electricity demand is driven by the nearly-doubled U.S. population over the course of the $21^{\text {st }}$ century (Figure S8(a)). Under both climate mitigation scenarios, coal-fired generation shrinks more significantly than in the reference and full trade scenarios (Figure S5). By 2095, nuclear and coal with CCS technology take up almost $60 \%$ of the total generation mix under RCP4.5_NucCCS (Figure S5(c)), while solar and wind under RCP4.5_RE meet approximately the same level of energy demand (Figure S5(d)). Overall, generation from nuclear, wind, solar, geothermal, and biomass technologies account for larger portions over time in all scenarios. The implications of this 
ongoing shift away from coal-dominant towards a mixture of fuels will strongly affect the associated water demand.

All seven scenarios project a decline in future electric-sector water withdrawal over the century (Figure 1(a)). Under the frozen scenario, which fixes the cooling mix to the 2005 level, a decline of $42 \%$ in water withdrawal from the base year is projected by 2095 . This decline is attributed to the retirement of existing coal power plants that use generic steam generation technology and to the implementation of the Integrated Gasification Combined Cycle (IGCC) technology in new coal power plants. In general, IGCC plants use $20 \%-50 \%$ less cooling water than conventional coal plants [Thompson, 2005]. In the other six scenarios, the rapid retirement of once-through cooling enhances the decline in water withdrawal. For example, with changes in the cooling technology mix, water withdrawal drops by $88 \%$ in the reference scenario. This implies by comparison with the frozen scenario that capital stock turnover could reduce water withdrawal by $46 \%$. The addition of water-saving technologies (advanced tech I) and an increasing share of dry cooling in dry states (advanced tech II) cause an additional 3\%-4\% decrease in water withdrawal by 2095 . The increase of the dry-cooling share largely accelerates the decline and produces a substantial reduction by mid-century. The two climate mitigation scenarios display different water withdrawal trajectories in the energy sector. The shares of traditional fuels such as coal and oil, which are usually water-intensive, decrease steadily under the RCP4.5_NucCCS - an effect that leads to a rapid decline in water withdrawal in the midcentury. In contrast, a slight upward trend is captured after mid-century, which is a response to the expanding electricity demand under RCP 4.5_NucCCS, driven by fuel substitution in the buildings and industrial manufacturing sectors. RCP4.5_RE encourages the deployment of renewable energies with low carbon emissions, which become prevalent later in the century. 
However, there is little reduction in water withdrawal compared to the reference and RCP4.5_NucCCS scenarios in the near future, because new capacity deployments initially use conventional hydrocarbon fuels (Figure S5(d)). The full trade scenario, which has a greater degree of spatial flexibility in matching generation with demand, actually reduces water withdrawal faster than the reference scenario. However, at the national level, the difference in water demands between these two scenarios becomes minimal after year 2055. In fact, by the end of the century, water withdrawals reach approximately the same level under all scenarios except for the frozen technology case.

Water consumption shows essentially the opposite trend to water withdrawal under all seven scenarios (Figure 1(b)). Consumption increases by a moderate 30\% from 2005 to 2095 in the frozen scenario, mostly because of expanding electricity demand. Under the reference scenario, the increase in water consumption is larger than the base year by $42 \%$, since lowerconsuming once-through cooling technologies are phased out in the conversion to closed-loop cooling. In spite of the capital turnover, water saving technologies could reduce water consumption from the reference scenario by as much as $32 \%-37 \%$, according to the advanced tech I and II scenarios. In contrast, the climate mitigation efforts of the RCP4.5_NucCCS scenario double water consumption by the end of the century, as a result of higher electricity demand and the use of carbon capture and storage and nuclear technologies. The RCP4.5_RE scenario, in contrast, constrains water consumption significantly by expanding the use of low water-intensity renewable fuels. Finally, the total U.S. electric-sector water consumption under the full trade scenario is very similar to the reference scenario. Overall, total electric water withdrawal (consumption) in the U.S. is projected to decrease (increase) under all seven scenarios. 


\section{Comparisons with other studies}

A comparison of our total U.S. electricity water withdrawal and consumption projections with similar studies shows similar water demands over the medium term. For example, total U.S. electricity water withdrawal in our reference scenario decreases by $66 \%$ from 2010 to 2050 , while the reference scenario decreases by $80.7 \%$ in Macknick et al. (2012) and $45 \%$ in Davies et al. (2013). Further, the RCP4.5_NucCCS scenario decreases by $86.5 \%$ over this time, compared to a $75.2 \%$ decrease in scenario 3 in Macknick et al. (2012), in which a carbon budget with coal with CCS and nuclear targets is assumed.

In contrast, U.S. total water consumption projections differ significantly between different studies. Total water consumption in our reference scenario grows by $20 \%$ from 2010 to 2050, while in Macknick et al. (2012), a decrease of $34.2 \%$ occurred over this time. This difference is a result of substantial coal and nuclear capacity replacement in Macknick et al. (2012) by natural gas combined cycle, which has a relatively lower consumption rate, as compared to the persistent fraction of coal and nuclear in GCAM-USA. Davies et al. (2013) estimate an increase of about $30 \%$ in the reference scenario. Blanc et al. (2014) project a $25 \%$ of increase in thermoelectric water consumption over the same time period in their no climate mitigation policy scenario (U.S. WET-UCE). In RCP4.5_NucCCS scenario, water consumption increases by $25.2 \%$, compared to an increase of $21.7 \%$ in scenarios 3 [Macknick et al., 2012a], while water consumption increases by $11.5 \%$ in the RCP4.5_RES scenario compared to decreases of $85.2 \%$ in scenarios 4 [Macknick et al., 2012a] and 28.5\% in U.S. WET-L1S [Blanc et al., 2014]. The different signs of changes result primarily from more aggressive deployment of renewable energies by 2050 in the latter two studies. 
Key drivers of electricity water demand at the state level

Next, we focus on state-level results based on the improved geographic and technological resolution of the GCAM-USA framework, and its provision of a full energy system model, including electricity demands and non-US regions. Analysis of the five key drivers in our scenarios also provides insight into the regional response of U.S. water sector to socioeconomic changes, future technological transitions, and climate mitigation policies.

a. Population growth

Population growth is one of the key drivers of changes in future U.S electric-sector water demand. As the total population increases, demands for goods and services that use energy also increase, which puts upward pressure on electricity demand. Further, with more people relocating to the South and West and smaller increases of population in the Midwest and Northeast U.S (Figure S8(b)), the changes in local energy demand and their associated water demands reflect U.S. population migration dynamics. Figure 2 shows that population growth partially explains the simulated increase in water consumption, particularly in the Southern U.S. However, population growth effects on water consumption in the West, Midwest, and Northeast are reduced by other factors, which are discussed in the following sections.

b. Cooling technology mix (reference vs. frozen)

Because water resources are more abundant in the Eastern U.S., the majority of the power plants in the Eastern U.S. use once-through cooling [Averyt et al., 2011]. Spatial results in the reference scenario show a complete phase-out of once-through power plants in many states (Figure 3(a)). However, under the frozen scenario, once-through systems remain dominant across the U.S. except in some western states such as California, which is abandoning once-through cooling technology in power plants due to stringent state regulations 
(http://www.waterboards.ca.gov/water_issues/programs/ocean/cwa316/policy.shtml)

(Figure

3(b)). Thus, a result of the cooling system conversions is the reduction of water withdrawal across all states except California (Figure 3(c)).

In terms of water consumption, once-through cooling all but disappears under the reference scenario, and closed-loop and non-cooling related water uses (namely, evaporation from hydro power plants and solar panel washing water) drive up consumptive water use in the U.S. (Figure S9(a)). Under the frozen scenario, in contrast, there is still considerable consumptive use from once-through cooling scattered across the U.S. (Figure S9(b)); therefore, the majority of states consume less water than under the reference scenario (Figure S9(c)).

c. Fuel portfolio (Ref vs. RCP4.5_NucCCS and RCP4.5_RE)

Future fuel mix under the reference scenario is described in Clarke et al. (2009). The two climate mitigation scenarios display different trajectories to meet the end-of-century mitigation goal (Figure S5(c) and (d)). To clarify the implications of climate mitigation policy on electricity water demand and the consequences of different stabilization paths, we first compare the results of the RCP 4.5_NucCCS and reference scenarios, and then compare RCP 4.5_NucCCS with RCP 4.5_RE.

In the RCP 4.5_NucCCS scenario, nuclear power plants become the dominant cooling water users by 2095 in Central and Eastern U.S. - regions that remain predominantly coalburning in the reference scenario (see Figures S10 and S11). Florida and Texas stand out in a comparison of water demands, since both states are highly populated with significant energy demand, but their electric-sector water demands exhibit different responses in the reference and RCP 4.5_NucCCS scenarios. 
While oil-fired power plants in Florida account for over 50\% of the total water withdrawal in 2005 , natural gas power plants dominate water withdrawal under the reference scenario by 2095, and nuclear power plants are the main users under RCP 4.5_NucCCS (Figure 4(b)). Overall, Florida withdraws 67\% less water under climate mitigation (Figure S10(c)), mainly because of the dramatic decrease in withdrawal requirements of natural gas power plants. These results point to an interesting trade-off. On one hand, climate mitigation favors nuclear, solar, and biomass power plants over fossil fuel power plants - for example, generation from natural gas plants is $46 \%$ less under RCP 4.5_NucCCS than under the reference scenario in 2095 (Figure 4(a)). On the other hand, under RCP 4.5_NucCCS, generic steam natural gas plants are gradually replaced by natural gas combined cycle (NGCC) and NGCC with carbon capture and sequestration (CCS). NGCC plants are less water-intensive than conventional steam plants and NGCC with CCS is limited to recirculating cooling in this study. In terms of water consumption, proportional increases from nuclear and biomass power plants affect RCP 4.5_NucCCS results significantly, with a nearly 50\% higher consumptive water use by 2095 (Figure 4(c)). Overall, climate mitigation results in a $62 \%$ drop in water withdrawal and $385 \%$ increase in water consumption as compared to a $36 \%$ drop and $226 \%$ increase, respectively, under the reference scenario. Therefore, the RCP4.5_NucCCS climate mitigation policy enhances both the reduction of water withdrawal and the increase in water consumption in Florida.

Texas switches from being coal- and gas-dominant to a diversified mix of fuels in both scenarios (Figure 4(d)). With climate mitigation policies, power plants in Texas withdraw (consume) approximately $3.7 \mathrm{~km}^{3} /$ year $\left(0.57 \mathrm{~km}^{3} /\right.$ year $)$ more water than without climate mitigation in 2095 (Figure 4(f)). Both increases are primarily attributable to nuclear power plants, which are assumed to withdraw only fresh water in Texas. Further, even with increasing 
electricity production from coal power plants, their water withdrawal decreases dramatically over time, because of the retirement of existing plants with once-through flow cooling systems. Finally, unlike the case of Florida, the climate mitigation policy of RCP4.5_NucCCS results in more water withdrawal and more consumption (70\% and 55\%, respectively) in Texas by 2095 . This is likely to exacerbate the already water-stressed conditions in Texas.

Under RCP 4.5_RE, water demands in Texas and Florida are not as significant as under RCP 4.5_NucCCS. Instead, by 2095, there is an overall decrease in water withdrawal and consumption across all states compared to the RCP 4.5_NucCCS scenario, with the exception of higher water withdrawal in Florida and higher water consumption in California, Nevada, Idaho, and Oregon (Figure 5). The higher water withdrawal in Florida is driven by the dominance of natural gas in the fuel mix, which accounts for $44.3 \%$ of the total water withdrawal in 2095 . The higher water consumption in some western states, such as California, is a result of the replacement of nuclear energy by geothermal energy, whose water consumption intensity is about five times higher than that of nuclear. In general, the aggressive nation-wide deployment of wind and solar energy substantially reduces both water withdrawal and consumption, more so in the East than in the West. The reduction is less pronounced in the West because of the adoption of geothermal energy, whose water demands are significant. Therefore, implementation approaches for end-of-century mitigation goals have evident implications for energy-sector water demands.

d. Electricity trade (reference vs. full trade)

Overall, the Central and Eastern U.S. display a decreasing trend in water withdrawal, and the Western U.S. shows increasing trends in both the reference and full trade scenarios (Figure 6). In general, the switch from once-through cooling to recirculating cooling contributes to the 
dramatic decline in water withdrawal in Central and Eastern U.S., but has minimal effect in the Western U.S. Instead, greater water demand seen in the Western U.S. is mainly a function of increasing electricity demand.

Overall, both scenarios exhibit similar behaviors (Figure 6); however, regional electricity markets have implications for the electricity water demand for some states. For example, under limited trading markets, a state can only trade electricity with neighboring states in the same electricity market - see Figure S1. But with the full trade option, states are permitted to import electricity from any of the other states without accounting for physical constraints. States like Florida, which ranks second in electricity consumption and 30th in total primary energy production (http://www.eia.gov/state/?sid=fl\#tabs-3), may then import electricity from states where energy is abundant and the cost is low. Therefore, with the full trade option, states including Texas, Florida, California, and Arizona generate less electricity internally, and meet demand instead by importing electricity from Northeastern states, which increase their electricity generation (Figure S12). Trade then results in the greater decrease in water withdrawal seen in Florida and Texas under the full trade scenario (Figure 6(a)). In terms of water consumption, the full trade option produces a moderate increase across the majority of states (Figure S13). Implications of driving factors at the state level

A number of strategies can reduce water use in the electric sector, including the use of cooling technologies that require less or even no water, or a switch to renewable energy technologies that require very little water for cooling. These nation-wide practices can lead to consistent effects across states (Figure 7); for example, the frozen and RCP 4.5_NucCCS scenarios display consistent, yet opposite, directions of change in water demand. Specifically, compared to the reference scenario, the frozen scenario increases water withdrawal and 
decreases water consumption across the majority of the states, while RCP 4.5_NucCCS increases water consumption in all states but maintains water withdrawal at the same level as the reference scenario (Figure 7(a) and 7(d)). The advanced tech scenarios slightly decreases water withdrawal and greatly reduces water consumption across all 50 states, and consistent across-state reductions in both water withdrawal and water consumption also occur in RCP 4.5_RE (Figure 7(e)), with the exception of a few states. However, full trade shows no discernible direction across all 50 states.

For individual states, heterogeneous effects are observed under different scenarios. For example, while change in the cooling technology mix does not affect the magnitude of water consumption in Texas, changes in the fuel portfolio increase water consumption in Texas by $54 \%$ under RCP 4.5_NucCCS but decrease it by $49 \%$ under RCP 4.5_RE. In contrast, change in the fuel mix does not affect water withdrawal in Illinois, but the cooling technology transition reduces water withdrawal by $71 \%$. More generally, national-scale implementations of capital stock turnover, climate mitigation policy and water-saving technologies each affect the water demands in homogenous ways in all states, but the net impacts differ from one state to another. The configuration of the electricity market, however, shows heterogeneous impacts to water demand (Figure 7(f)).

\section{Trade-off between water withdrawal and consumption}

The three types of electric sector changes discussed here - adoption of renewable energy technologies, conversion to closed-loop cooling, and switching to less water-intensive generation technologies - affect water withdrawal and consumption significantly by 2095 , with $42 \%$ to $91 \%$ reductions in withdrawal and $4.2 \%$ to $80 \%$ increases in consumption. 
Water pricing applies to water withdrawal rather than consumptive use, which creates an incentive to reduce water withdrawal quantity to minimize cost. In addition, current environmental regulations (Clean Water Act 316 (b)) encourage less water withdrawal to minimize threats to local water sources from discharged waste heat and increased turbulence in the water body. Previous studies [Adam et al., 2013; Hightower and Pierce, 2008] indicate that drought will likely exacerbate challenges to the nation's electric power market, with scarcitydriven price increases and reliability problems. However, with significant water withdrawal reductions, an event like the 2008 drought in the Southeast, which forced power plants to shut down for days, might be avoided [Webber, 2012]. Nevertheless, recirculating cooling technologies impose a tradeoff between relatively low water-withdrawal and relatively high water-consumption compared with once-through cooling. In addition, a shift away from oncethrough cooling systems in coastal areas that use saline water to inland recirculating systems that primarily consume freshwater will affect watersheds and water availability differently, depending on local conditions. For example, although $98 \%$ of the once-through cooling water used for thermoelectric generation in California is seawater, recent regulations that require alternatives to traditional once-through cooling may result in greater freshwater use [Fencl et al., 2012]. These new regulations aim to improve conditions for marine life in California, but will also likely add substantial renovation costs to as many as 19 power plants.

The frozen scenario helps to clarify the importance of this trade-off between water withdrawal and consumption (Figure 8). Relative to the reference scenario, the frozen scenario reduces consumptive water use but has more than five times the water withdrawal. Advanced tech I and II scenarios reduce both water withdrawal and consumption, but the associated high cost and low efficiency of dry cooling make them economically less-favorable options for every 
state. Previous work [Turchi et al., 2010] suggests that the performance penalty for CSP facilities switching from wet cooling to dry cooling results in an annual reduction in output of $2 \%-5 \%$ and an increase in the levelized cost of producing energy of 3\%-8\%, depending on local climatic conditions. Using national averages, the annual performance penalty for switching from wet cooling to dry cooling is $6.8 \%$ for nuclear plants, $1.7 \%$ for combined cycle plants, and $6.9 \%$ for other fossil plants (including coal and natural gas steam plants).

Fthenakis and Kim (2010) found that carbon emission standards may reduce electricsector water use. However, our results indicate that the different approaches to enforce $\mathrm{CO}_{2}$ emission reductions could affect electric-sector water demands significantly (Figure 8). For example, while the RCP 4.5_NucCCS scenario exhibits an $85 \%$ reduction in total water withdrawal, climate mitigation via nuclear and CCS drives an increase in total water consumption of $80 \%$ in $2095,27 \%$ higher than under reference scenario, because of the high water intensities of nuclear and biomass technologies. In addition, CCS generally increases water consumption by 37\%-95\% [Grubert and Kitasei, 2010], and increases energy production costs by $21 \%-91 \%$, depending on the type of power plant [Metz et al., 2005]. The significant water consumption and high cost of CCS-based power plants may render them infeasible for some regions. Climate mitigation via renewables (RCP 4.5_RE) constrains the increase in water consumption to only $9.8 \%$ from 2005 , and accelerates the reduction in withdrawal to $95 \%$. But the assumption of no nuclear energy expansion and no CCS technology adoption in this scenario makes it an unrealistic approach to meet the stabilization target [Eom et al., 2014]; an alternative approach would be to limit the expansions of these technologies [Iyer et al., 2014] and examine the response of water demand. All in all, decisions affecting electric-sector technology choices must include water considerations to avoid unintended negative consequences on water resources. 
In conclusion, current policies and regulations greatly encourage reduction in water withdrawal, but these reductions come at the cost of increased consumption under all of the scenarios, especially RCP 4.5_NucCCS. This water use trade-off may introduce new problems for water-scarce regions as consumptive water is not returned to the system immediately after use. Advanced water-saving technologies, a higher adoption rate of dry cooling, and aggressive deployment of renewable energies may help to maintain relatively low consumptive use of water; however, a trade-off exists between their associated costs and the resulting water saving.

\section{Summary and conclusions}

We estimated electric-sector water withdrawal and consumption at the state level in the U.S. using the GCAM-USA under seven scenarios. Five major driving forces were studied individually: 1) changing socioeconomics and growing electricity demands, 2) cooling system shifts, 3) adoption of water-saving technologies, 4) adoption of climate mitigation policy, and 4) constraints on electricity trading across states.

Several key conclusions from the above analyses follow.

1) Although the scenarios project a significant expansion in U.S. electricity generation as population grows, U.S. electric-sector water withdrawals decline by $42 \%$ - $91 \%$ by 2095 while water consumptions increase by $4.2 \%-80 \%$. The wide spectrum of variation is a result of compounding factors related to population, cooling technology mix, watersaving technology, fuel portfolio, and electricity trading options.

2) Population change shows a positive relationship with electric-sector water demand variation, especially in the South, where increasing relocation of population is projected. Water resources in the Southern states could experience greater pressure to meet the growing demands for electricity. 
3) Capital stock turnover drives regional heterogeneity over time. By 2095, once-through cooling is phased out in the majority of states, causing Central and Eastern U.S. to experience substantial drops in water withdrawals, while the Western U.S. will likely experience a moderate increase over the century.

4) The different approaches to enforce $\mathrm{CO} 2$ emission reductions could affect water demand in the energy sector significantly. Mitigation through renewable energies substantially reduces water demand, more so in the East than in the West. However, climate mitigation strategies focusing on CCS and nuclear power will have less favorable water consumption effects.

5) The flexibility of electricity trading reduces water withdrawal to a larger extent in the full trade scenario for some states. Energy-scarce yet demand-intensive states such as Florida appear to benefit from the full trade option, despite projected population increases in the state.

6) Changes in the electricity generation mix and in water cooling technologies can produce conflicting effects on water consumption and withdrawal; i.e., decreasing water withdrawals, but increasing water consumption - a clear indication of their trade-off.

In conclusion, the results of this work show agreement with the existing literature on estimating electricity water demand at a larger scale [Blanc et al., 2014; Davies et al., 2013; Macknick et al., 2012a]. The study goes beyond the existing efforts by incorporating greater technological and geographical detail, allowing us to understand the complex interactions between the energy and water sectors with future technological transitions. This work also suggests the need for future work on energy-sector water competition with other water demand sectors in the GCAM-USA framework. Future research of this nature should include water 
supply constraints and climate change impacts on water temperatures to provide greater insight at policy-relevant scales. Potential future research includes, but is not limited to, expanding the GCAM-USA framework to countries and regions outside the U.S., resolving the sectoral water competition mechanism outside the U.S., incorporating desalinated water and groundwater, evaluating different climate mitigation and adaptation policies, and assessing environmental impacts of energy sector transformation processes.

\section{Acknowledgements}

This research was supported by the Office of Science of the U.S. Department of Energy through the Integrated Assessment Research Program as part of the Regional Integrated Assessment Modeling (RIAM) project. This research leveraged capabilities that were funded by the Platform for Regional Integrated Modeling and Analysis Initiative (PRIMA), which was conducted under the Laboratory Directed Research and Development Program at Pacific Northwest National Laboratory (PNNL). PNNL is operated for DOE by Battelle Memorial Institute under contract DE-AC05-76RL01830. The views and opinions expressed in this paper are those of the authors alone.

The Union of Concerned Scientists (UCS) Database is the result of efforts by members of the EW3 Baseline Assessment Team, which included Kristen Averyt (research lead, University of Colorado-Boulder, NOAA Western Water Assessment), Jeremy Fisher (Synapse Energy Economics), Annette Huber-Lee (Tufts University), Aurana Lewis (Duke University), Jordan Macknick (National Renewable Energy Laboratory), Nadia Madden (Union of Concerned Scientists), John Rogers (Union of Concerned Scientists), and Stacy Tellinghuisen (Western Resource Advocates). We are also grateful to Shazia Davis and KC Hallett (National Renewable 
Energy Laboratory) and Emily Briley and Seth Sheldon (Civil Society Institute) for their contributions.

\section{References}

Adam, P. P., S. A. Nawaf, D. W. Mort, E. W. Michael, and T. A. David (2013), Changing the spatial location of electricity generation to increase water availability in areas with drought: a feasibility study and quantification of air quality impacts in Texas, Environmental Research Letters, 8(3), 035029.

Averyt, K., J. Fisher, A. Huber-Lee, A. Lewis, J. Macknick, N. Madden, J. Rogers, and S. Tellinghuisen (2011), Freshwater use by U.S. power plants: Electricity's thirst for a precious resource. A report of the Energy and Water in a Warming World initiativeRep., Union of Concerned Scientists, Cambridge, MA.

Blanc, E., K. Strzepek, A. Schlosser, H. Jacoby, A. Gueneau, C. Fant, S. Rausch, and J. Reilly (2014), Modeling U.S. water resources under climate change, Earth's Future, 2(4), 2013 EF000214.

Brenkert, M., S. J. Smith, S. Kim, and H. Pitcher (2003), Model Documentation for the MiniCAMRep., PacificNorthwest National Laboratory, Richland, Wasghinton.

Byers, E. A., J. W. Hall, and J. M. Amezaga (2014), Electricity generation and cooling water use: UK pathways to 2050, Global Environmental Change, 25(0), 16-30.

Clarke, L., J. Lurz, M. Wise, J. Edmonds, S. Kim, H. Pitcher, and S. J. Smith (2007), Model Documentation for the MiniCAM Climate Change Science Program Stabilization ScenariosRep., Pacific Northwest National Laboratory Richland, Washington.

Clemmer, S., J. Rogers, S. Sattler, J. Macknick, and T. Mai (2013), Modeling low-carbon US electricity futures to explore impacts on national and regional water use, Environmental Research Letters, 8(1), 015004.

Davies, E. G. R., P. Kyle, and J. A. Edmonds (2013), An integrated assessment of global and regional water demands for electricity generation to 2095, Advances in Water Resources, 52(0), 296-313.

Easterling, W. E. (1997), Why regional studies are needed in the development of full-scale integrated assessment modelling of global change processes, Global Environmental Change, 7(4), 337-356.

Edmonds, J., and J. Reilly (1985), Global Energy: Assessing the Future, Oxford University Press, New York.

EIA (2013a), Annual Energy Outlook 2013: with projections to 2040Rep., U.S. Energy Information Administration.

EIA (2013b), The Electricity Market Module of the National Energy Modeling System Model Documentation 2013Rep., U.S. Energy Information Administration, Washington DC.

Eom, J., J. Edmonds, V. Krey, N. Johnson, T. Longden, G. Luderer, K. Riahi, and D. P. Van Vuuren (2014), The impact of near-term climate policy choices on technology and emission transition pathways, Technological Forecasting and Social Change(In press).

EPA (2006), EPA U.S. National MARKAL Database: Database DocumentationRep., United States Environmental Protection Agency, Washington DC.

EPRI (2000), Water \& Sustainability (Volume 3): U.S. Water Consumption for Power Production-The Next Half CenturyRep. 1006786, 57 pp, Palo Alto, CA. 
EPRI (2007), Assessment of Cooling Water Intake Structure Impacts to California Coastal FisheriesRep., 132pp pp, EPRI, Palo Alto, CA.

EPRI (2010), Water use for electricity generation and other sectors: recent changes (1985-2005) and future projections (2005-2030)Rep., Electric Power Research Institute.

Feeley Iii, T. J., T. J. Skone, G. J. Stiegel Jr, A. McNemar, M. Nemeth, B. Schimmoller, J. T. Murphy, and L. Manfredo (2008), Water: A critical resource in the thermoelectric power industry, Energy, 33(1), 1-11.

Fencl, A., V. Clark, V. Mehta, D. Purkey, M. Davis, and D. Yates (2012), Water for Electricity: Resource Scarcity, Climate Change and Business in a Finite WorldRep., 52 pp, Stockholm Environment Institute, Sweden.

Fthenakis, V., and H. C. Kim (2010), Life-cycle uses of water in U.S. electricity generation, Renewable and Sustainable Energy Reviews, 14(7), 2039-2048.

Grubert, E., and S. Kitasei (2010), How Energy Choices Affect Fresh Water Supplies: A Comparison of U.S. Coal and Natural GasRep., 20 pp, World Watch Institute.

Hejazi, M., et al. (2014), Long-term global water projections using six socioeconomic scenarios in an integrated assessment modeling framework, Technological Forecasting and Social Change, 81(0), 205-226.

Hightower, M., and S. A. Pierce (2008), The energy challenge, Nature, 452(7185), 285-286.

Iyer, G., N. Hultman, J. Eom, H. McJeon, P. Patel, and L. Clarke (2014), Diffusion of lowcarbon technologies and the feasibility of long-term climate targets, Technological Forecasting and Social Change(In press).

Kenny, J. F., N. L. Barber, S. S. Huston, K. S. Linsey, J. K. Lovelace, and M. A. Maupin (2009), Estimated use of water in the United States in 2005Rep., 52p pp, U.S. Geological Survey Circular 1344.

Kim, S., J. Edmonds, J. Lurz, S. Smith, and M. Wise (2006), The object-oriented energy climate technology systems (ObjECTS) framework and hybrid modeling of transportation in the MiniCAM Long-term, global integrated assessment model, Energy J., 27, 63-92.

Kyle, P., E. G. R. Davies, J. J. Dooley, S. J. Smith, L. E. Clarke, J. A. Edmonds, and M. Hejazi (2013), Influence of climate change mitigation technology on global demands of water for electricity generation, International Journal of Greenhouse Gas Control, 13(0), 112123.

Loulou, R., and M. Labriet (2008), ETSAP-TIAM: the TIMES integrated assessment model Part I: Model structure, $C M S, 5(1-2), 7-40$.

MacKichan, K. A. (1957), Estimated use of water in the United States, 1955Rep., 21p pp, Geological Survery Circular 398.

Macknick, J., S. Scattler, K. Averyt, S. Clemmer, and J. Rogers (2012a), The water implications of generating electricity: water use across the United States based on different electricity pathways through 2050 Environ. Res. Lett., 7, 10pp.

Macknick, J., R. Newmark, G. Heath, K. C. Hallett, J. Meldrum, and S. Nettles-Anderson (2012b), Operational Water Consumption and Withdrawal Factors for Electricity Generating Technologies: A Review of Existing Literature, Environmental Research Letters, Vol. 7(4), 10pp.

Marcucci, A., and H. Turton (2014), Induced technological change in moderate and fragmented climate change mitigation regimes, Technological Forecasting and Social Change(In press). 
Messner, S., and L. Schrattenholzer (2000), MESSAGE-MACRO: linking an energy supply model with a macroeconomic module and solving it iteratively, Energy, 25(3), 267-282.

Metz, B., O. Davidson, H. d. Coninck, M. Loos, and L. Meyer (2005), IPCC special report on carbon dioxide capture and storage, Medium: X; Size: 440; 423.443 MB pages pp.

Murray, C. R., and E. B. Reeves (1977), Estimated use of water in the United States in 1975Rep., 46 pp, U.S. Geological Survey Circular 765.

NETL (2009), Estimating Freshwater Needs to Meet Future Thermoelectric Generation Requirements Report Rep., p109 pp, National Energy Technology Laboratory, DOE/NETL-400/2010/1339

NETL (2011), Estimating Freshwater Needs to Meet Future Thermoelectric Generation Requirements - 2011 UpdateRep., National Energy Technology Laboratory, NETL/DOE2011/1523

Paltsev, S., J. M. Reilly, H. D. Jacoby, A. C. Gurgel, G. E. Metcalf, A. P. Sokolov, and J. F. Holak (2008), Assessment of US GHG cap-and-trade proposals, Climate Policy, 8(4), 395-420.

Ross, M. T., A. A. Fawcett, and C. S. Clapp (2009), U.S. climate mitigation pathways post-2012: Transition scenarios in ADAGE, Energy Economics, 31, Supplement 2(0), S212-S222.

Short, W., P. Sullivan, T. Mai, M. Mowers, C. Uriarte, N. Blair, D. Heimiller, and A. Martinez (2011), Regional Energy Deployment System (ReEDS)Rep., National Renewable Energy Laboratory.

Solley, W. B., R. R. Pierce, and H. A. Perlman (1998), Estimated use of water in the United StatesRep., 79 pp, U.S. Geological Survery Circular 1200.

Thompson, J. (2005), Integrated gasification combined cycle (IGCC) - Environmental performance, paper presented at Platts IGCC symposium, Pittsburge, June 2-3.

Thomson, A., et al. (2011), RCP4.5: a pathway for stabilization of radiative forcing by 2100, Climatic Change, 109(1-2), 77-94.

Turchi, C., M. Wagmer, and C. Kutscher (2010), Water Use in Parabolic Trough Power Plants: Summary Results from WorleyParsons' AnalysesRep., National Renewable Energy Laboratory, Golden, CO.

Vickers, A. (2002), Water use and conservation, 464 pp., WaterPlow Press.

Webber, M. (2012), Will drought cause the next blackout?, in The New York Times, edited.

Webster, M., P. Donohoo, and B. Palmintier (2013), Water-CO2 trade-offs in electricity generation planning, Nature Clim. Change, 3(12), 1029-1032.

Zhou, Y., et al. (2014), Modeling the effect of climate change on U.S. state-level buildings energy demands in an integrated assessment framework, Applied Energy, 113(0), 10771088. 
(a)
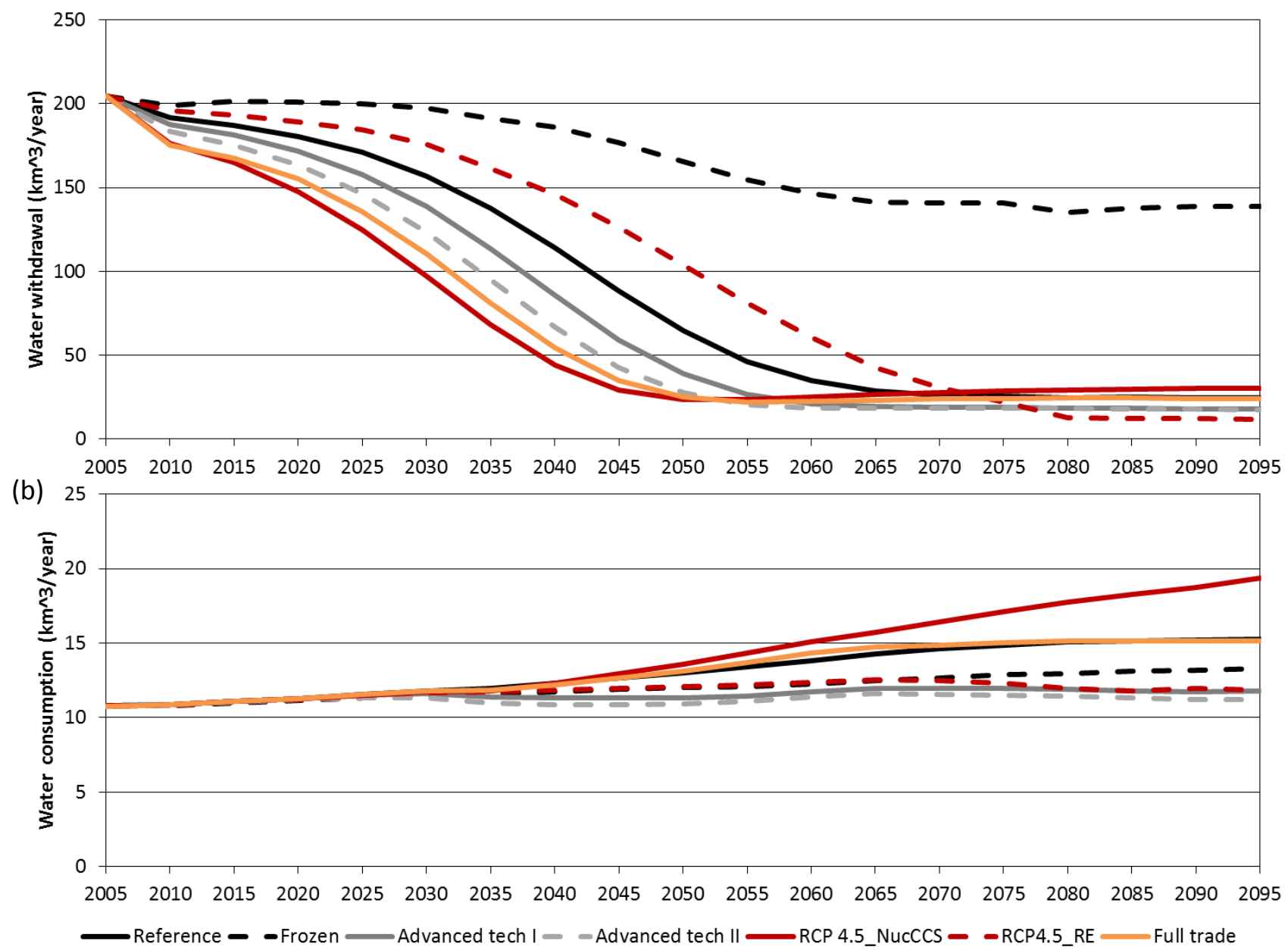

Figure 1 (a) Projected electric-sector water withdrawal under all scenarios (b) Projected electric-sector water consumption under all scenarios 


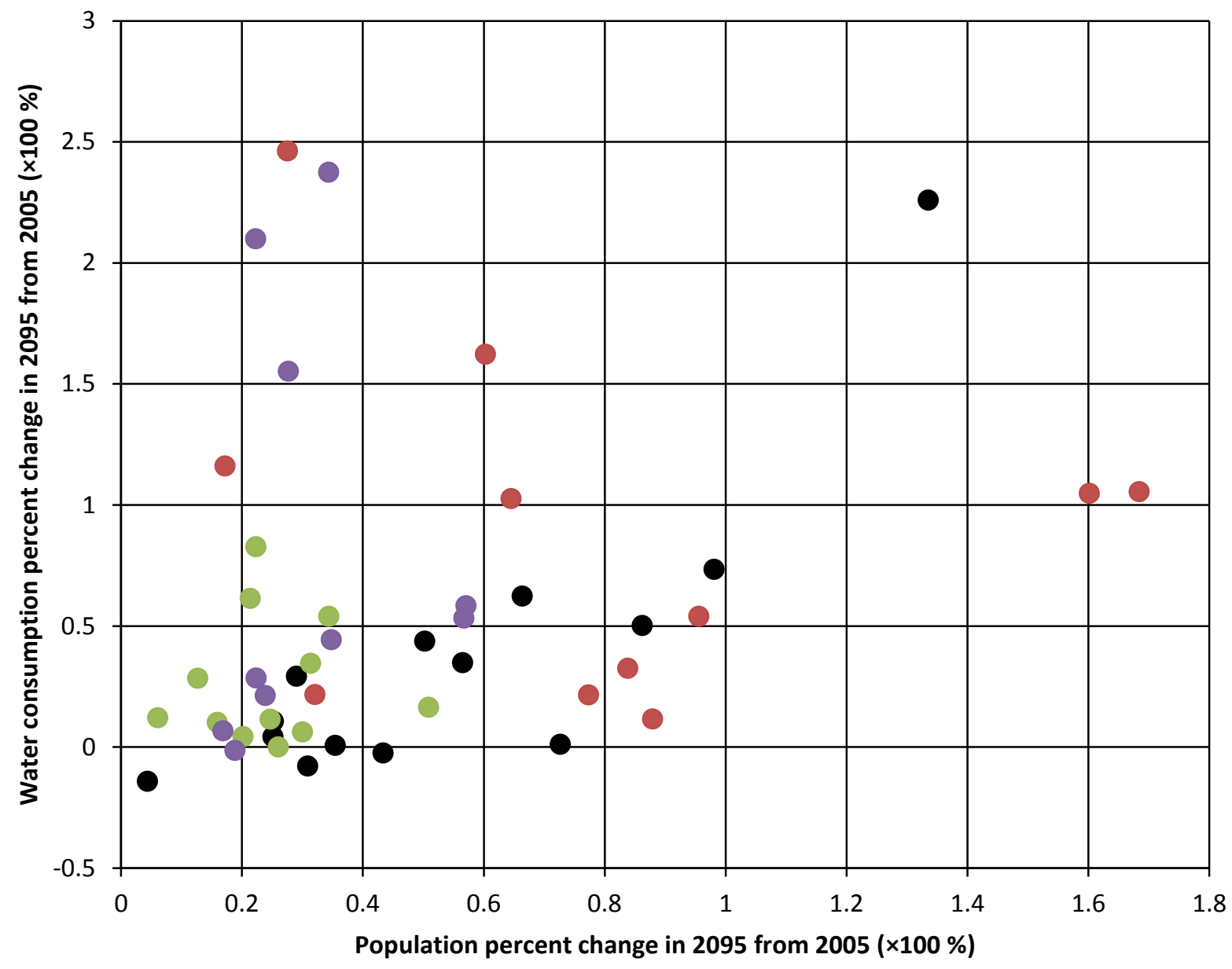

- South West Midwest Northeast

Figure 2 Population percent change in 2095 from 2005 vs. water consumption percent change in 2095 from 2005 


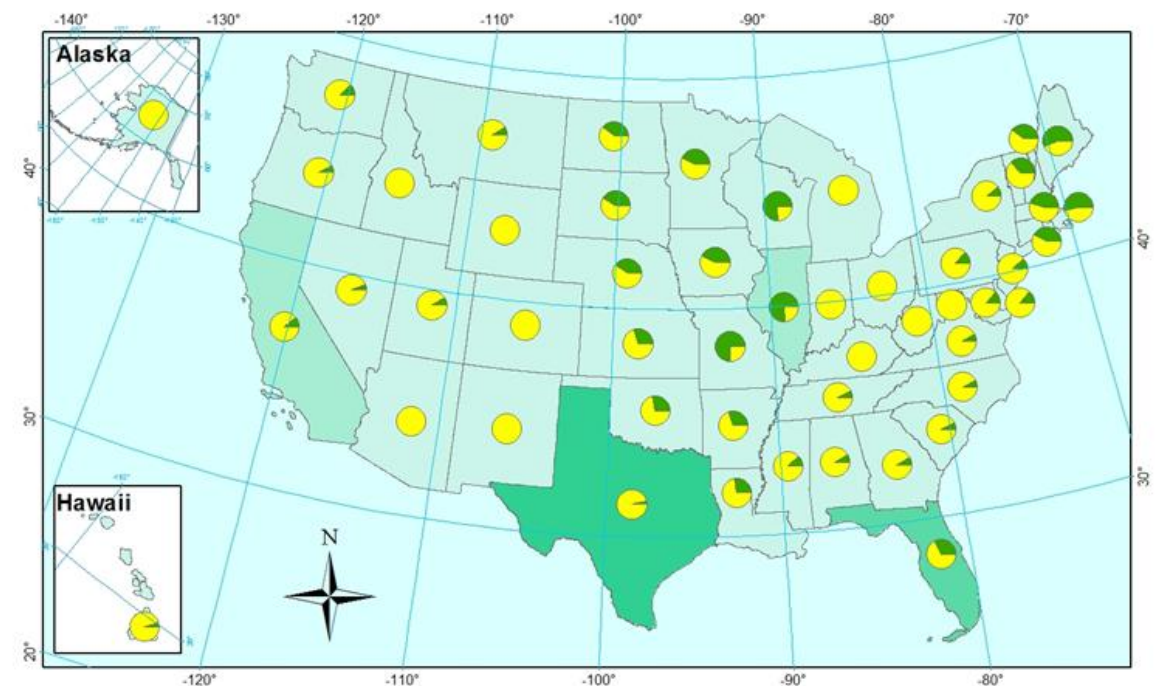

(b)

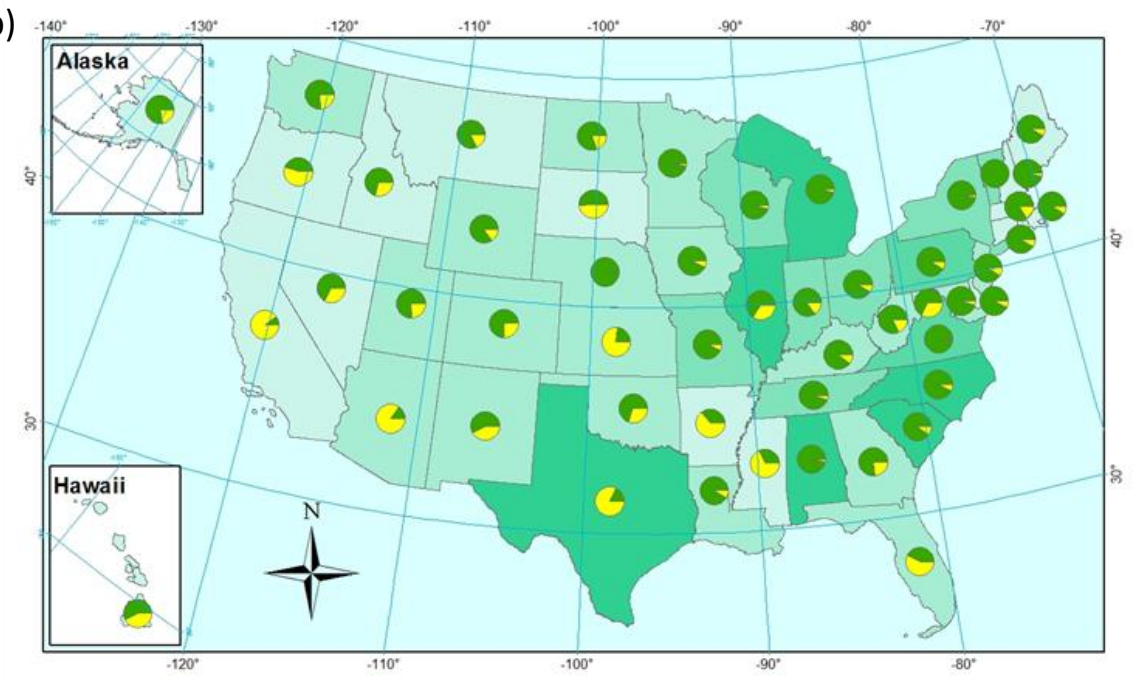

\section{Cooling technology}

Water withdrawal $\left(\mathrm{km}^{3} / \mathrm{yr}\right)$
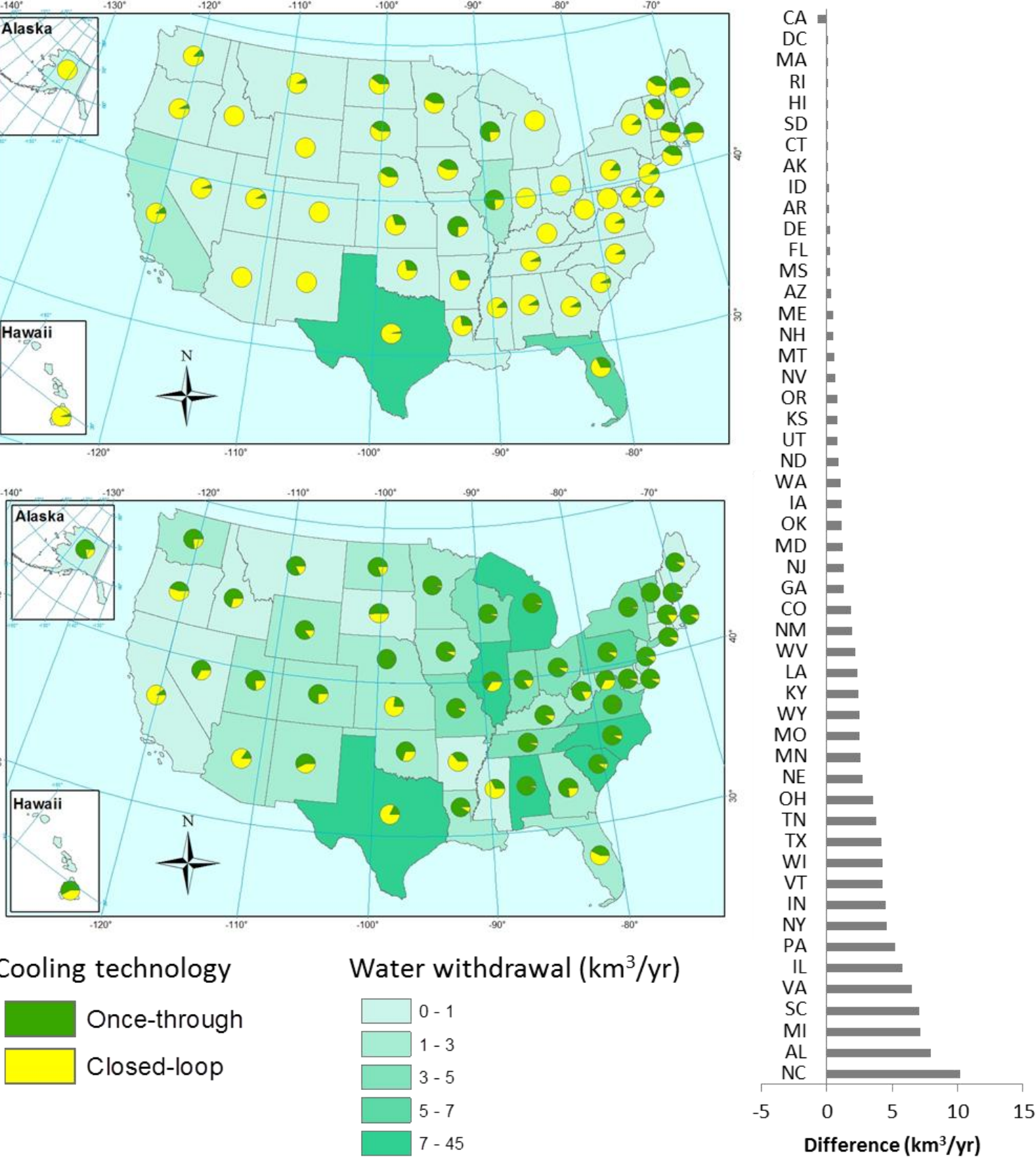

Figure 3 (a) State level electric-sector water withdrawal by cooling technology for the year 2095 under the Reference scenario (b) State level electric-sector water withdrawal by cooling technology for the year 2095 under the Frozen scenario (c) The difference in water withdrawal between Frozen and Reference scenarios for the year 2095 
(a) REF RCP 4.5_NucCCS

FL
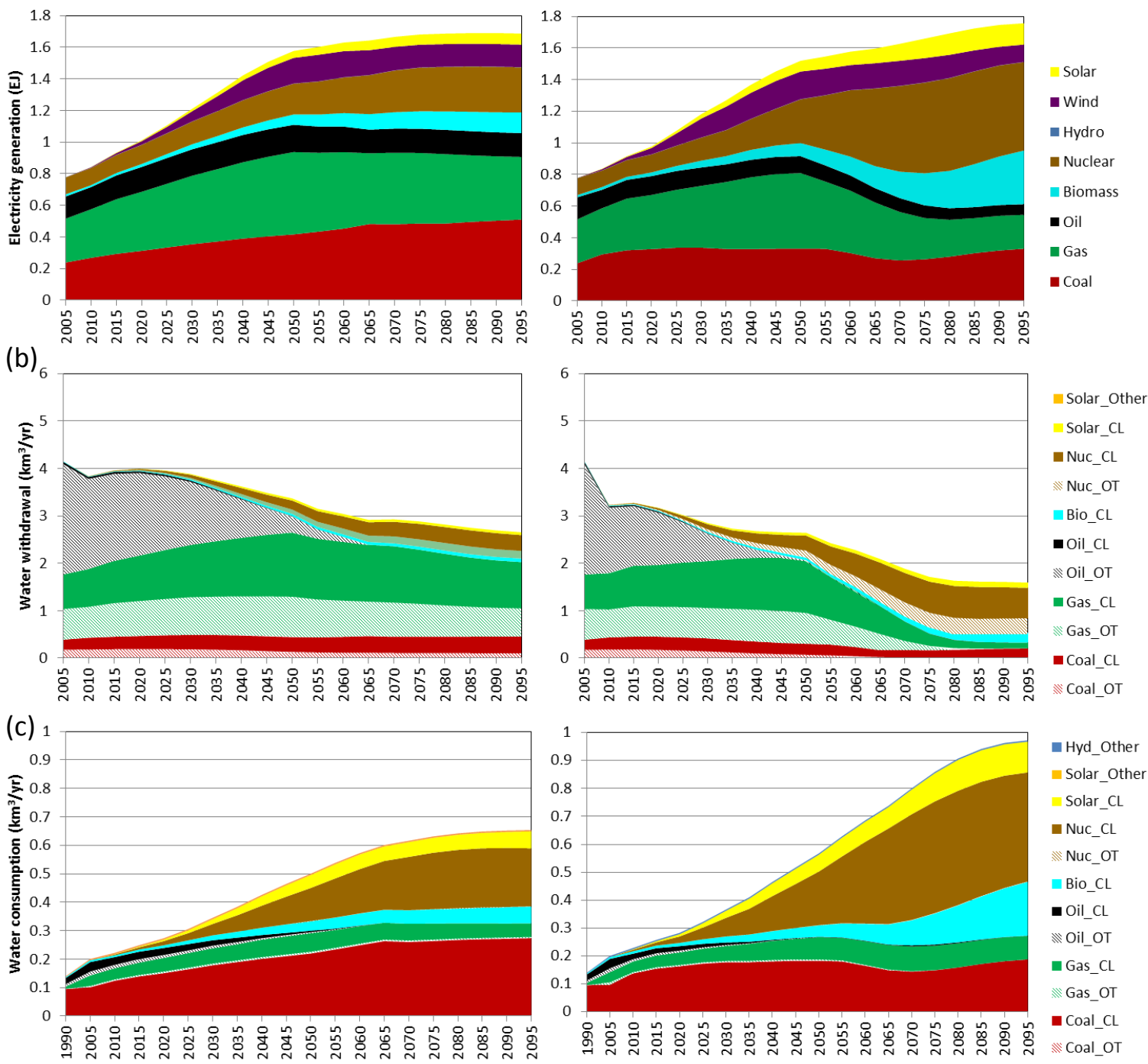
(d)

TX

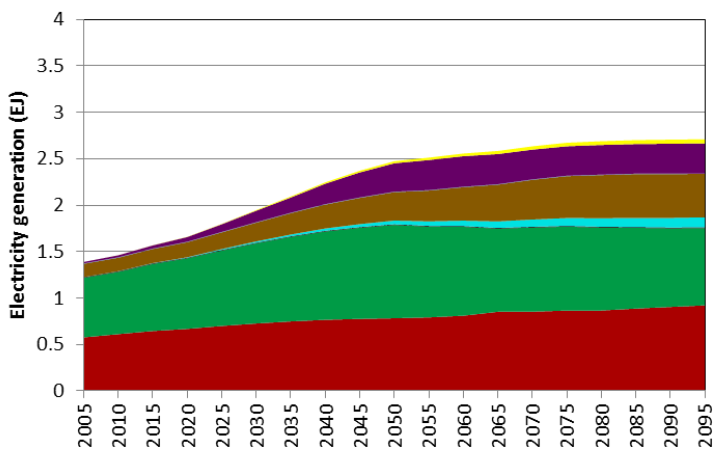

$(\mathrm{e})$
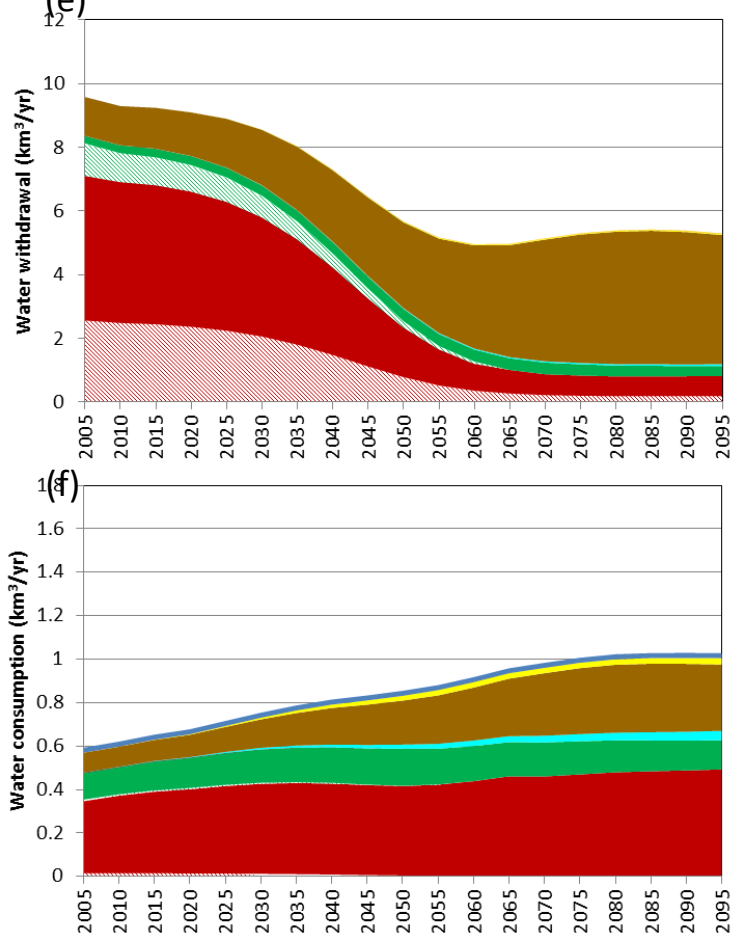

RCP 4.5_NucCCS
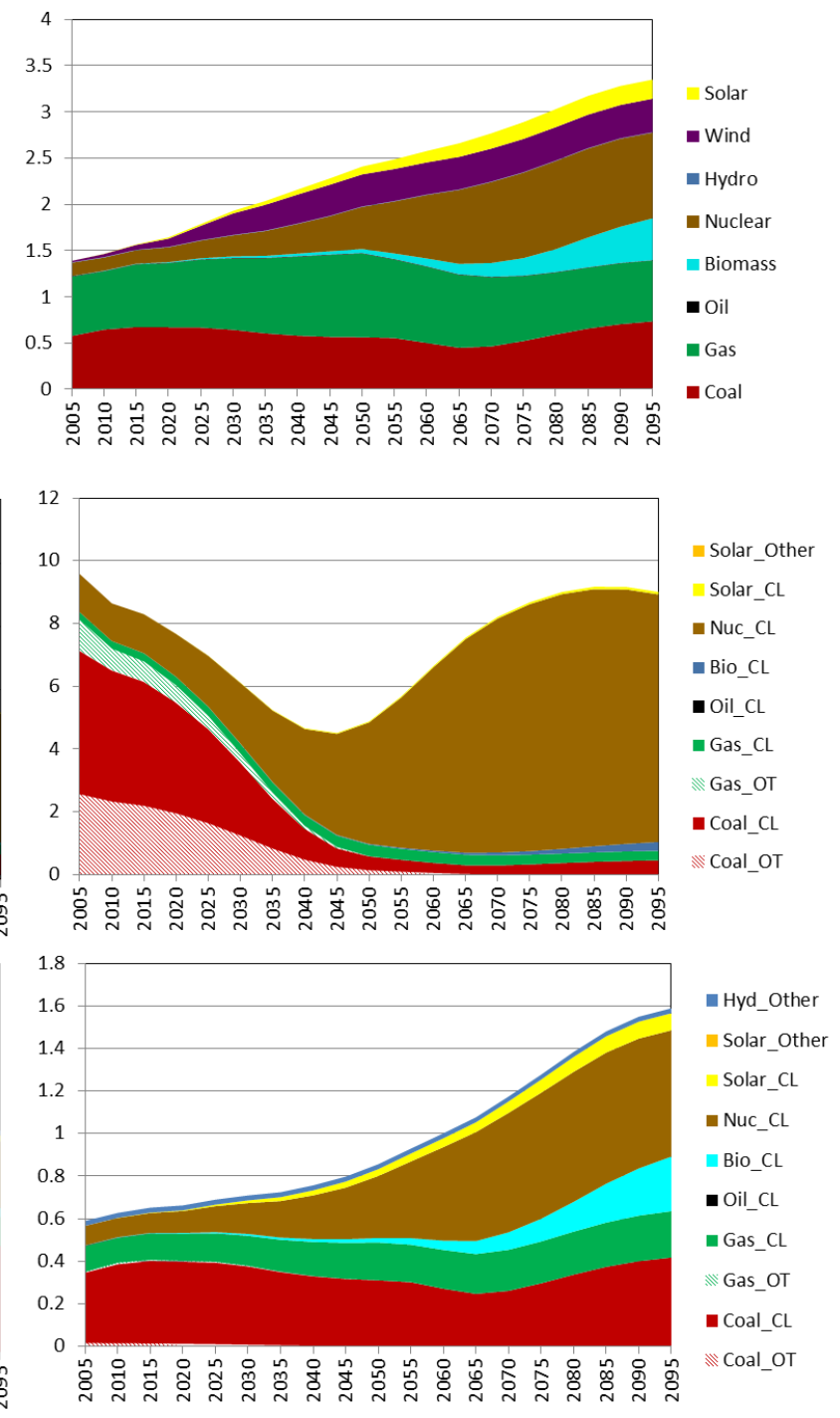

Figure 4 (a) Electricity generation in Texas under the Reference and RCP 4.5_NucCCS scenarios (b) Electric-sector water withdrawal in Texas under reference and RCP 4.5_NucCCS scenarios (c) Electric-sector water consumption in Texas under the Reference and RCP 4.5_NucCCS scenarios (d) Electricity generation in Florida under the Reference and RCP 4.5_NucCCS scenarios (e) Electric-sector water withdrawal in Florida under the Reference and RCP 4.5_NucCCS scenarios (f) Electricsector water consumption in Florida under the Reference and RCP 4.5_NucCCS scenarios ("CL" is closed loop, including recirculating and cooling pond; "ОT" is once-through; "Other" is none cooling related water use, usually associated with solar power and hydro power) 

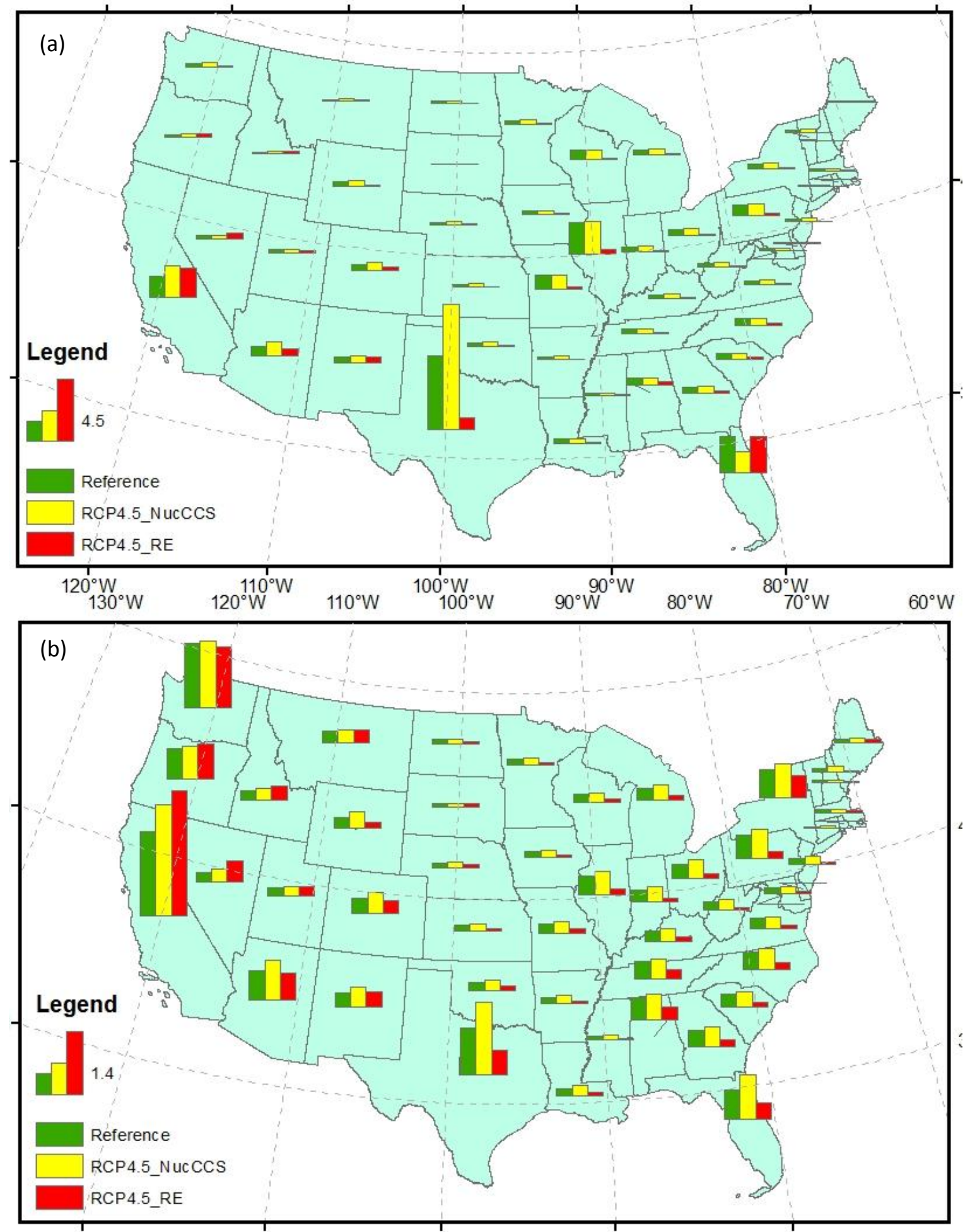

Figure 5 (a) 2095 state level electric-sector water withdrawal under the Reference, RCP4.5_NucCCS and RCP4.5_RE scenarios (b) 2095 state level electric-sector water consumption under the Reference, RCP4.5_NucCCS and RCP4.5_RE scenarios 
(a)

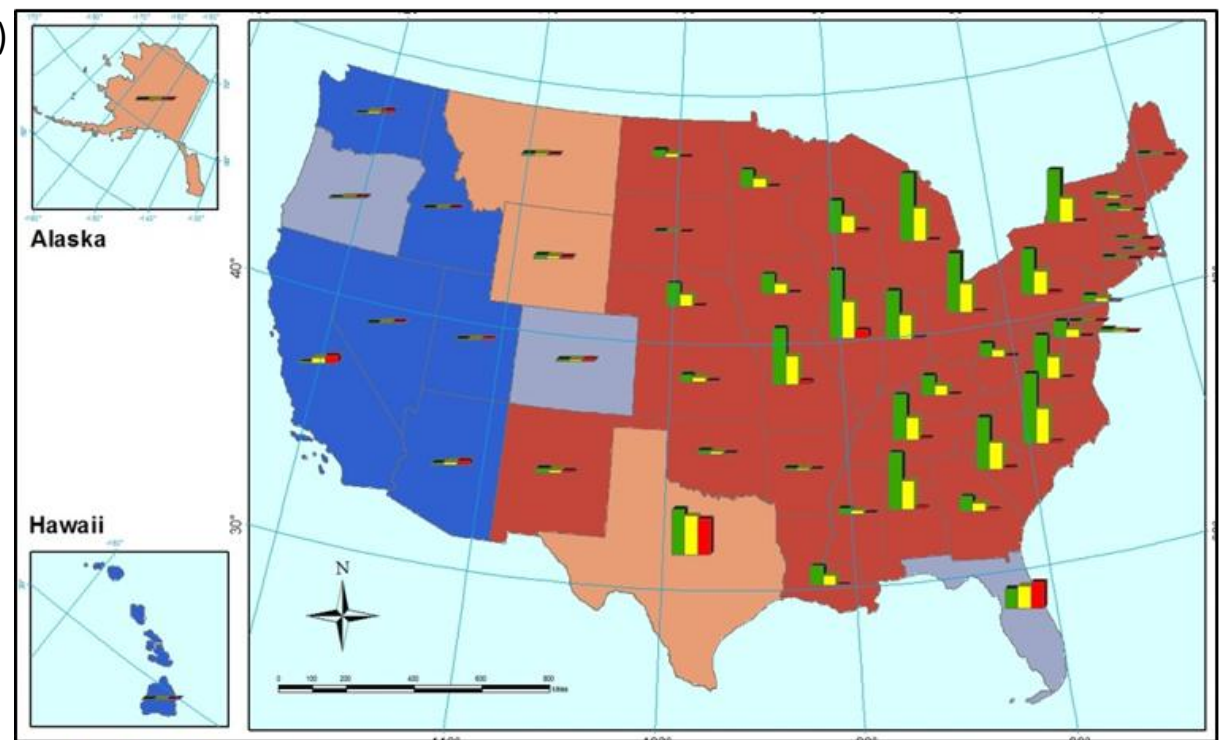

(b)
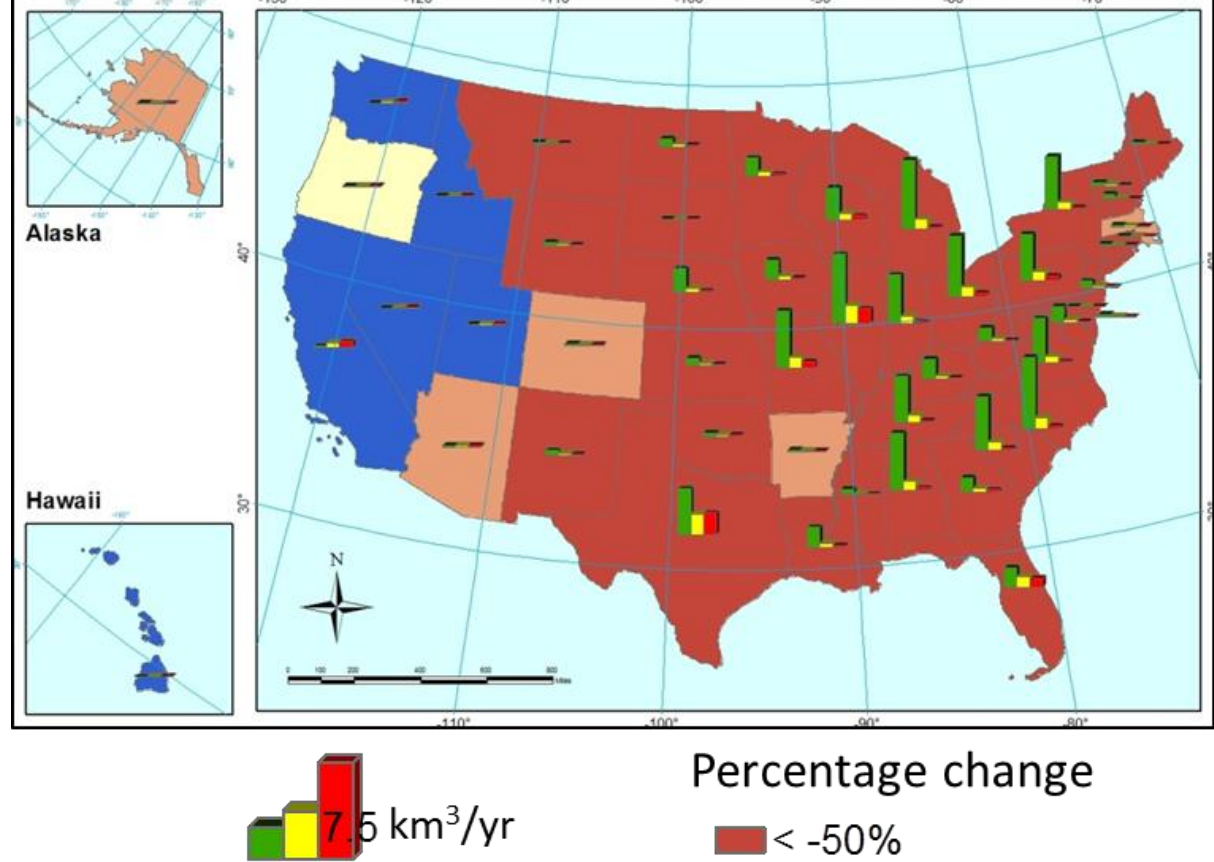

2005

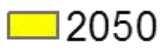

2095

\section{Percentage change}

$<-50 \%$

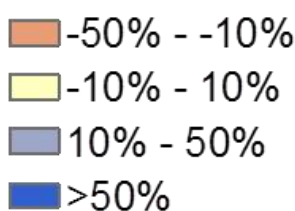

(c)

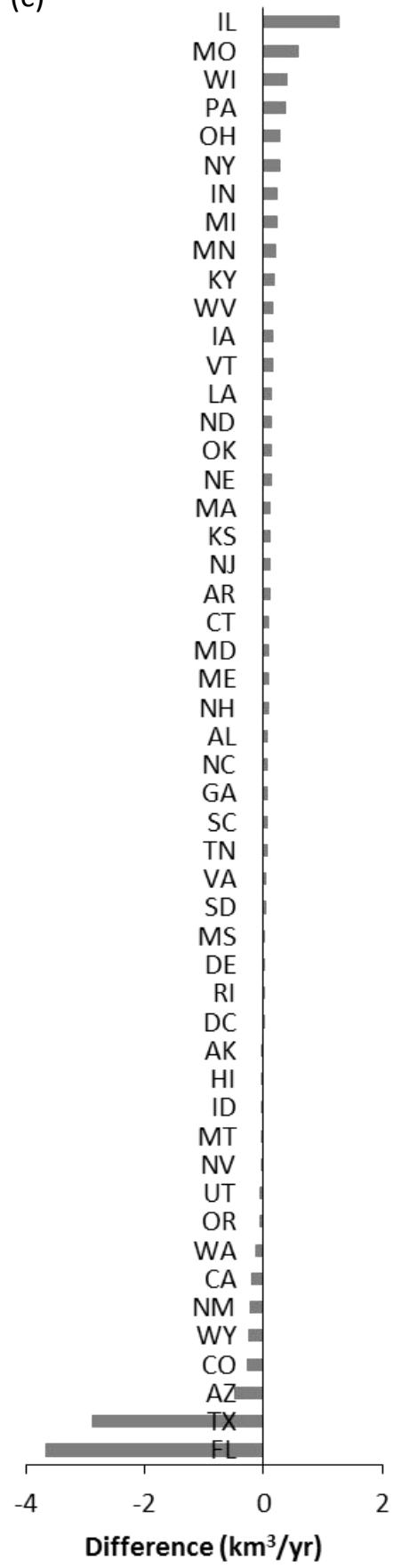

Figure 6 (a) State level electric-sector water withdrawal under the Reference scenario (b) State level electric-sector water withdrawal under the Full trade scenario (c) The difference in water withdrawal between the Full trade and Reference scenarios for the year 2095 
(a)

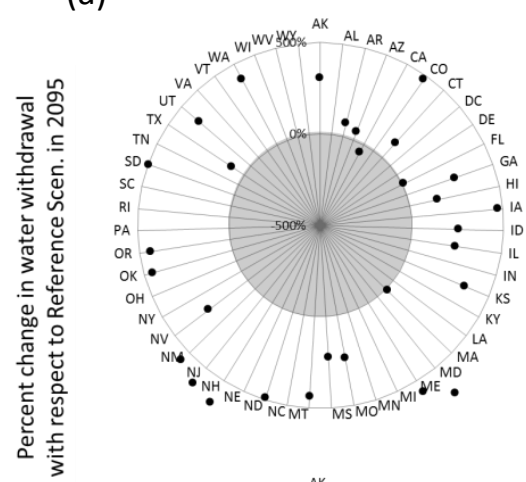

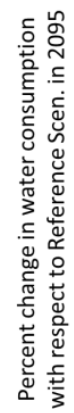

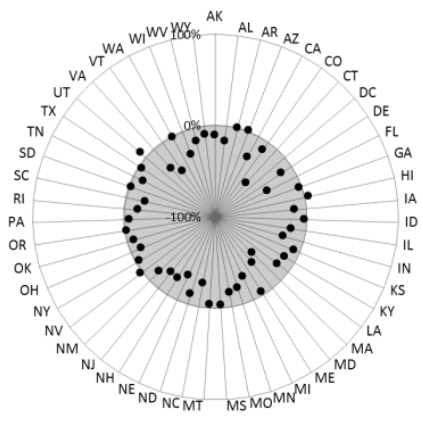

(d)
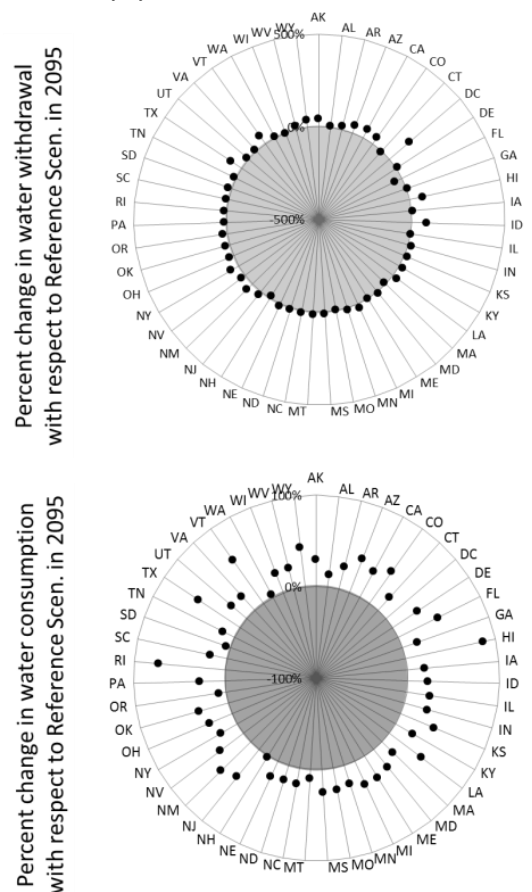

(b)
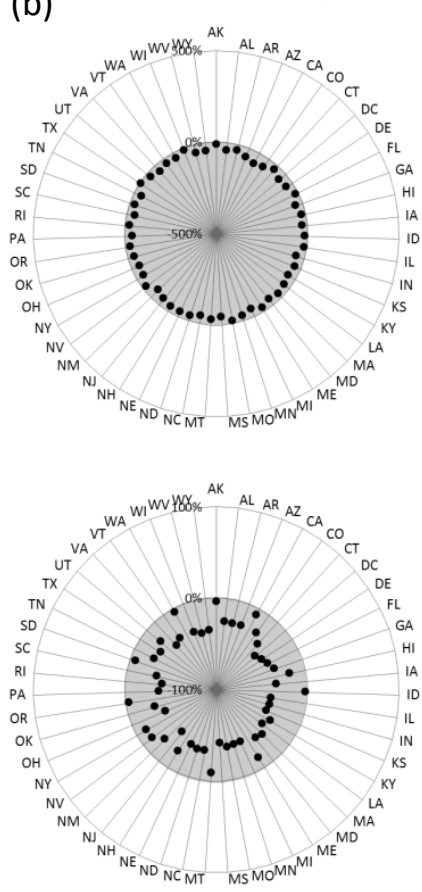

(e)
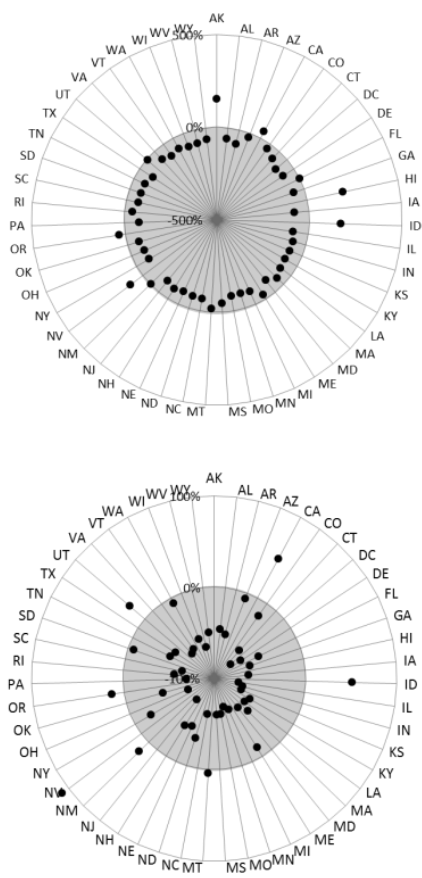

(c)
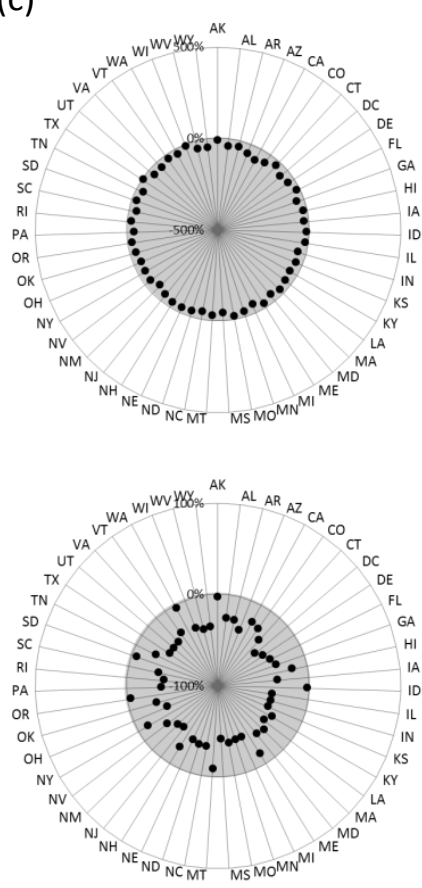

(f)

Full Trade
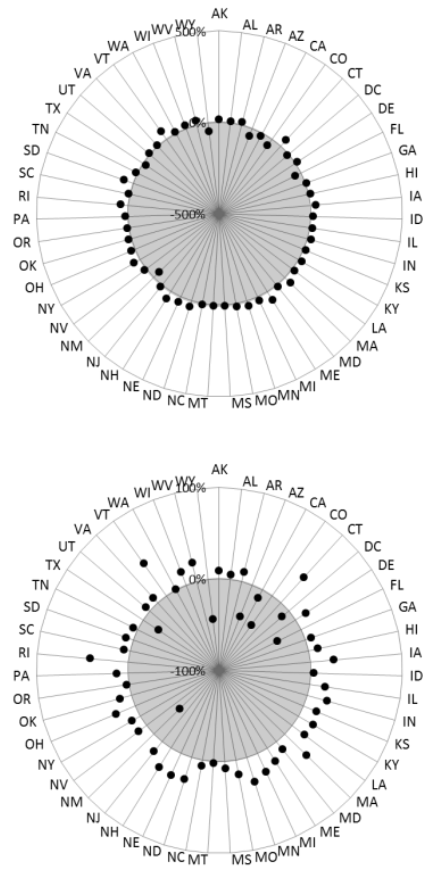

Figure 7 (a) Percent change in water withdrawal and consumption respect to the reference scenario in 2095 under the frozen tech scenario. (b) Percent change in water withdrawal and consumption respect to the reference scenario in 2095 under the advanced tech I scenario. (c) Percent change in water withdrawal and consumption respect to the reference scenario in 2095 under the advanced tech II scenario. (d) Percent change in water withdrawal and consumption respect to the reference scenario in 2095 under the RCP4.5_NucCCS scenario. (d) Percent change in water withdrawal and consumption respect to the reference scenario in 2095 under the RCP4.5_RE scenario. (f) Percent change in water withdrawal and consumption respect to the reference scenario in 2095 under the full trade scenario. 


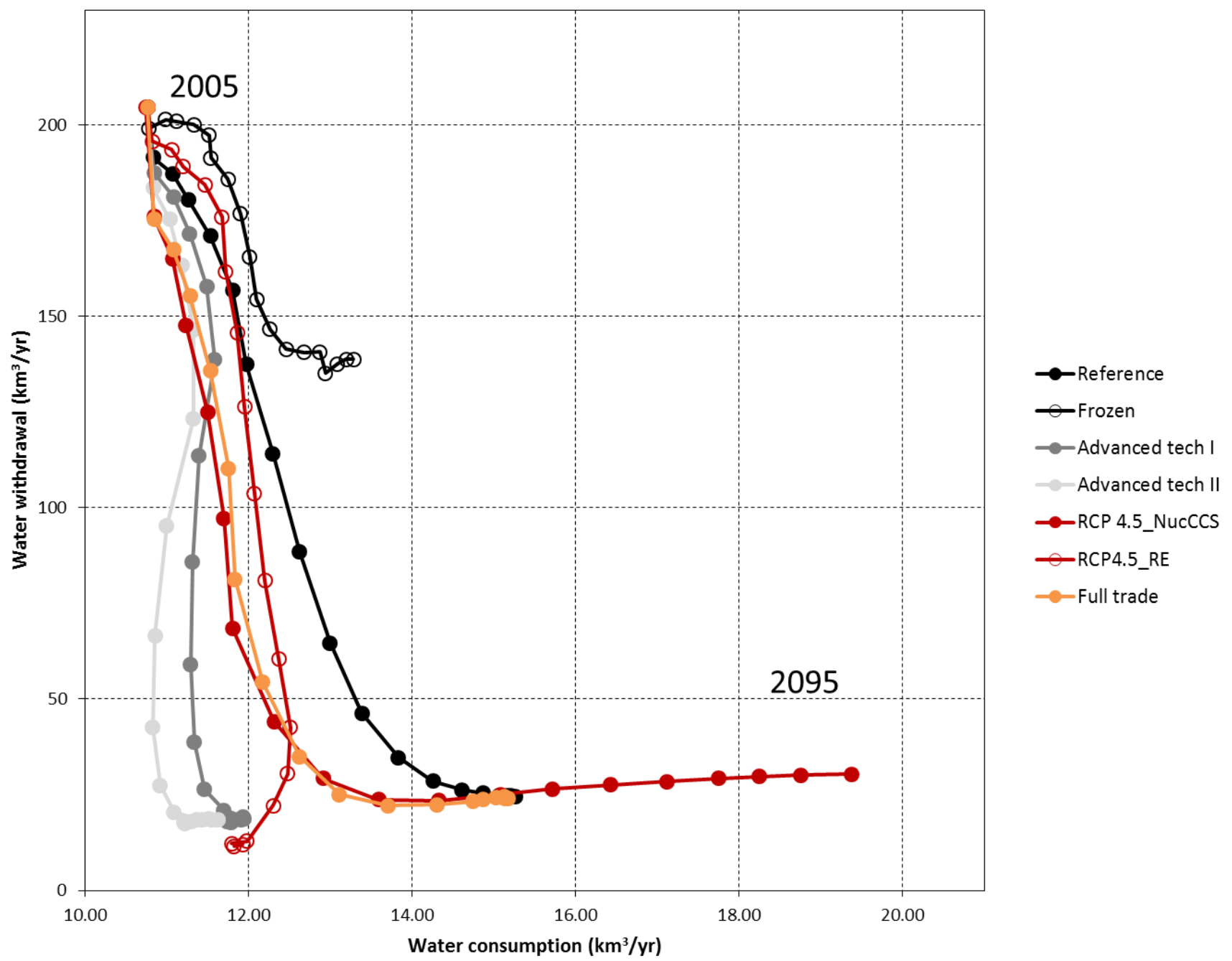

Figure 8 Water consumption vs. water withdrawal under all six scenarios (each point is one five-year period). 
Table 1 Configuration details for the six scenarios

\begin{tabular}{|c|c|c|c|c|}
\hline $\begin{array}{l}\text { Scenario } \\
\text { names }\end{array}$ & $\begin{array}{l}\text { Water saving } \\
\text { technology (same as } \\
\text { Davies et al. (2013)) }\end{array}$ & $\begin{array}{l}\text { Electricity } \\
\text { trading }\end{array}$ & Climate mitigation & Future cooling technology share \\
\hline $\begin{array}{l}\text { Frozen } \\
\text { scenario }\end{array}$ & No adoption & $\begin{array}{l}\text { Limited } \\
\text { trading }\end{array}$ & No & Fix to base year share for each state \\
\hline Reference & No adoption & $\begin{array}{l}\text { Limited } \\
\text { trading }\end{array}$ & No & $\begin{array}{l}\text { Average share of 2000-2008 for each NEMS region, } 2010 \text { and } \\
\text { onward }\end{array}$ \\
\hline $\begin{array}{l}\text { Advanced } \\
\text { tech I }\end{array}$ & Full adoption & $\begin{array}{l}\text { Limited } \\
\text { trading }\end{array}$ & No & $\begin{array}{l}\text { Average share of } 2000-2008 \text { for each NEMS region, } 2010 \text { and } \\
\text { onward }\end{array}$ \\
\hline $\begin{array}{l}\text { Advanced } \\
\text { tech II }\end{array}$ & Full adoption & $\begin{array}{l}\text { Limited } \\
\text { trading }\end{array}$ & No & $\begin{array}{l}\text { Average share of } 2000-2008 \text { for each NEMS region except for } \\
\text { designated dry states (In dry states, assume 30\% dry cooling for } \\
\text { non-nuclear fuels and decrease closed-loop cooling } \\
\text { correspondingly), } 2010 \text { and onward }\end{array}$ \\
\hline $\begin{array}{l}\text { RCP } \\
\text { 4.5_NucCCS }\end{array}$ & No adoption & $\begin{array}{l}\text { Limited } \\
\text { trading }\end{array}$ & $\begin{array}{l}\text { Mitigate through } \\
\text { nuclear and CCS } \\
\text { technology }\end{array}$ & $\begin{array}{l}\text { Average share of } 2000-2008 \text { for each NEMS region, } 2010 \text { and } \\
\text { onward. }\end{array}$ \\
\hline RCP4.5_RE & No adoption & $\begin{array}{l}\text { Limited } \\
\text { trading }\end{array}$ & $\begin{array}{l}\text { Mitigate through } \\
\text { renewable energies }\end{array}$ & $\begin{array}{l}\text { Average share of } 2000-2008 \text { for each NEMS region, } 2010 \text { and } \\
\text { onward. }\end{array}$ \\
\hline Full trade & No adoption & Full trading & No & $\begin{array}{l}\text { Average share of } 2000-2008 \text { for each NEMS region, } 2010 \text { and } \\
\text { onward. }\end{array}$ \\
\hline
\end{tabular}


Ms. Lu Liu is a Post Master Research Associate at the Joint Global Change Research Institute (JGCRI), where she has been employed since September 2012. Her research generally includes the development of global hydrologic models and implementation of global and regional sectoral water demand models from an integrated assessment framework. Lu received both her B.S. and M.S. in Environmental Science at the University of Oklahoma. Prior to joining JGCRI, she worked as a Research Assistant at the University of Oklahoma and as a GIS technician at the Oklahoma Gas \& Electricity Energy Corp

Dr. Mohamad Hejazi is a Research Scientist at the Joint Global Change Research Institute (JGCRI), a collaboration between the University of Maryland and the Pacific Northwest National Laboratory (PNNL). He holds a Ph.D. (2009) from the University of Illinois at UrbanaChampaign, and a B.S. (2002) and M.S. (2004) degrees from the University of Maryland, College Park. His research interests include: global hydrologic modeling, global and regional sectoral water demand modeling, and quantifying the effects of climate change, human activities, and climate policies on hydrology and water scarcity.

Mr. Pralit Patel is a Research Scientist at the Joint Global Change Research Institute (JGCRI), a collaboration between the University of Maryland and the Pacific Northwest National Laboratory (PNNL). He is involved developing integrated assessment models. He is currently researching how to utilize software engineering and design pattern to create scalable models that take advantage modern computing facilities enabling researches to expand temporal, spacial and technological detail to better understand the implications of addressing climate change.

Mr. Page Kyle is a Research Scientist at the Joint Global Change Research Institute (JGCRI), a collaboration between the University of Maryland and the Pacific Northwest National Laboratory (PNNL). His research generally addresses technology and mitigation of greenhouse gas emissions, from an integrated assessment framework. Specific areas of research have included development of representations of renewable energy resources, secondary energy production, final energy demand, non-CO2 greenhouse gas emissions, and most recently, greenhouse gas emissions from bioenergy production systems. He received a B.A. from Dartmouth College in Earth Sciences and Economics, and a M.S. in ecology from Utah State University.

Dr. Evan Davies is an Assistant Professor in the Department of Civil and Environmental Engineering at the University of Alberta, Canada. His primary interests lie in the fields of water resources, systems thinking and modeling, and sustainable development. His work focuses on systems modeling of water resources and their socio-economic and environmental context. He received a PhD (Civil and Environmental Engineering, 2007) from the University of Western Ontario, London, Ontario, Canada, and M.E.S. (Environment and Resource Studies, 2003), and B.A.Sc. (Systems Design Engineering, 2001), from the University of Waterloo, Waterloo, Ontario, Canada. 
Dr. Yuyu Zhou is a geographical scientist at the Joint Global Change Research Institute, a partnership of the Pacific Northwest National Laboratory (PNNL) and the University of Maryland. He received his B.S. degree in geography and M.S. degree in remote sensing from Beijing Normal University and his Ph.D. degree in environmental sciences from University of Rhode Island. His research focuses on applications of remote sensing, GIS, Integrated Assessment Modeling, and spatial analysis to understand the problems of global environmental change and their potential solutions.

Dr. Leon Clarke is a Senior Scientist and leads the Integrated Modeling and Energy Group at the Joint Global Change Research Institute (JGCRI), a collaboration between the University of Maryland and the Pacific Northwest National Laboratory (PNNL). Dr. Clarke's current research focuses on the role of technology in addressing climate change, international climate policy, scenario analysis, the interactions between climate impacts and mitigation, and integrated assessment model development. Dr. Clarke holds B.S. and M.S. degrees in Mechanical Engineering from U.C. Berkeley and M.S. and Ph.D. degrees in Engineering Economic Systems and Operations Research from Stanford University.

Dr. Jae Edmonds is a Chief Scientist and Laboratory Fellow at the Joint Global Change Research Institute (JGCRI), a collaboration between the University of Maryland and the Pacific Northwest National Laboratory (PNNL), and Adjunct Professor of Public Policy at the University of Maryland at College Park. His research in the areas of long-term, global, energy, economy, and climate change spans three decades, during which time he published several books, numerous scientific papers and made countless presentations. He serves on numerous panels and advisory boards related to energy, technology, the economy and climate change. His received his Ph.D. in the field of Economics from Duke University in 1975. 